\title{
IL-6 trans-signaling licenses mouse and human tumor microvascular gateways for trafficking of cytotoxic T cells
}

\author{
Daniel T. Fisher, ${ }^{1}$ Qing Chen, ${ }^{1,2}$ Joseph J. Skitzki, ${ }^{1}$ Jason B. Muhitch, ${ }^{1}$ Lei Zhou, ${ }^{1}$ \\ Michelle M. Appenheimer, ${ }^{1}$ Trupti D. Vardam, ${ }^{1}$ Emily L. Weis, ${ }^{1}$ Jessica Passanese, ${ }^{1}$ \\ Wan-Chao Wang, ${ }^{1}$ Sandra O. Gollnick, ${ }^{3}$ Mark W. Dewhirst, ${ }^{4}$ Stefan Rose-John, ${ }^{5}$ \\ Elizabeth A. Repasky, ${ }^{1}$ Heinz Baumann, ${ }^{6}$ and Sharon S. Evans ${ }^{1}$
}

\begin{abstract}
${ }^{1}$ Department of Immunology, Roswell Park Cancer Institute, Buffalo, New York, USA. ${ }^{2}$ Cancer Biology and Genetics Program, Memorial Sloan-Kettering Cancer Center, New York, New York, USA. ${ }^{3}$ Department of Cell Stress Biology, Roswell Park Cancer Institute, Buffalo, New York, USA. ${ }^{4}$ Department of Radiation Oncology, Duke University Medical Center, Durham, North Carolina, USA. ${ }^{5}$ Department of Biochemistry, Christian-Albrechts-University, Kiel, Germany. ${ }^{6}$ Department of Molecular and Cellular Biology, Roswell Park Cancer Institute, Buffalo, New York, USA.
\end{abstract}

\begin{abstract}
Immune cells are key regulators of neoplastic progression, which is often mediated through their release of cytokines. Inflammatory cytokines such as IL-6 exert tumor-promoting activities by driving growth and survival of neoplastic cells. However, whether these cytokines also have a role in recruiting mediators of adaptive anticancer immunity has not been investigated. Here, we report that homeostatic trafficking of tumor-reactive $\mathrm{CD8}^{+} \mathrm{T}$ cells across microvascular checkpoints is limited in tumors despite the presence of inflammatory cytokines. Intravital imaging in tumor-bearing mice revealed that systemic thermal therapy (core temperature elevated to $39.5^{\circ} \mathrm{C} \pm 0.5^{\circ} \mathrm{C}$ for 6 hours) activated an IL-6 trans-signaling program in the tumor blood vessels that modified the vasculature such that it could support enhanced trafficking of CD8 ${ }^{+}$ effector/memory $\mathrm{T}$ cells (Tems) into tumors. A concomitant decrease in tumor infiltration by Tregs during systemic thermal therapy resulted in substantial enhancement of Tem/Treg ratios. Mechanistically, IL-6 produced by nonhematopoietic stromal cells acted cooperatively with soluble IL- 6 receptor- $\alpha$ and thermally induced gp130 to promote E/P-selectin- and ICAM-1-dependent extravasation of cytotoxic $\mathrm{T}$ cells in tumors. Parallel increases in vascular adhesion were induced by IL-6/soluble IL-6 receptor- $\alpha$ fusion protein in mouse tumors and patient tumor explants. Finally, a causal link was established between IL-6-dependent licensing of tumor vessels for Tem trafficking and apoptosis of tumor targets. These findings suggest that the unique IL-6-rich tumor microenvironment can be exploited to create a therapeutic window to boost $T$ cell-mediated antitumor immunity and immunotherapy.
\end{abstract}

\section{Introduction}

Immune cells have emerged as key regulators of neoplastic progression via disparate activities that are dependent on context and cell type. Tumor-associated macrophages, neutrophils, and CD4 ${ }^{+}$ Th2 lymphocytes promote the initiation of tumorigenesis as well as tumor persistence and metastasis by releasing proinflammatory cytokines such as TNF, IL-1 $\beta$, IL-6, and IL-4 $(1,2)$. Conversely, $\mathrm{CD}^{+} \mathrm{T}$ lymphocytes are potent effectors of adaptive tumor immunity through their production of IFN- $\gamma$ as well as initiation of perforin/granzyme or Fas ligand-dependent cytolysis following TCRmediated engagement by tumor antigens $(3,4)$. The presence of $\mathrm{CD}^{+} \mathrm{T}$ cells in ovarian, colorectal, and melanoma patient tumors is correlated with improved survival and can be a better prognostic indicator than conventional tumor staging (5-7).

Successful cancer immunity requires large numbers of tumorspecific cytolytic $\mathrm{CD}^{+} \mathrm{T}$ cells as well as their efficient entry into neoplastic tissues. Tumor-specific $\mathrm{CD}^{+}$effector $\mathrm{T}$ cells (Teffs) are normally present at a low frequency in cancer patients (i.e., $0.1 \%-4 \%$ of $\mathrm{CD}^{+} \mathrm{T}$ cells), but can be expanded to up to $50 \%$ of

Authorship note: Daniel T. Fisher and Qing Chen contributed equally to this work. Conflict of interest: Stefan Rose-John is the inventor on patents describing Hyper-IL-6 and sgp130Fc and is a shareholder of the CONARIS Research Institute. Citation for this article: J Clin Invest. 2011;121(10):3846-3859. doi:10.1172/JCI44952. total circulating $\mathrm{CD}^{+} \mathrm{T}$ cells by vaccination or adoptive $\mathrm{T}$ cell transfer therapy $(3,4,8)$. A conundrum has been that these $\mathrm{CD}^{+}$ $\mathrm{T}$ cells are largely ineffective in controlling tumor growth in vivo. While $\mathrm{CD}^{+} \mathrm{T}$ cell localization in tumors is widely recognized as an essential determinant of tumor immunity, there is surprisingly little known about the rate of $\mathrm{T}$ cell trafficking across tumor microvascular checkpoints. Transcriptional profiling has identified several molecules that correlate positively (e.g., ICAM-1) or negatively (e.g., endothelin B receptor and receptor of $\mathrm{G}$ protein signaling 5 [RGS5]) with $\mathrm{CD}^{+} \mathrm{T}$ cell infiltration in murine or patient tumors $(7,9,10)$. However, in the absence of direct imaging of $\mathrm{T}$ cell interactions within tumor vessels, it has been difficult to resolve the mechanisms controlling extravasation, since infiltration over days to weeks (murine models) or years (patients) depends not only on $\mathrm{T}$ cell trafficking across vascular barriers, but also on the number of Teffs in the circulating pool and $\mathrm{T}$ cell fate (e.g., apoptosis, survival, proliferation, retention, and egress) within the interstitial compartment. Estimates that approximately $40 \%$ of intratumoral $\mathrm{CD}^{+} \mathrm{T}$ cells undergo cell division over a 24-hour period (11) suggest that this factor alone could have a major impact on the measured number of tumor-resident $\mathrm{T}$ cells.

Clues regarding the molecular mechanisms governing $\mathrm{T}$ cell trafficking to tumors stem from observations at nonmalignant sites where extravasation depends on stepwise adhesive interac- 
tions within blood vessels. High endothelial venules (HEVs) in LNs and Peyer patches support high rates of homeostatic trafficking of naive and central memory $\mathrm{T}$ cells during routine immune surveillance $(12,13)$. Homeostatic trafficking of Teffs is limited at extralymphoid sites, but increases sharply during inflammation (14). Cytokine-inducible tethering/rolling molecules (e.g., E- and P-selectin, VCAM-1, and mucosal addressin cell adhesion molecule-1 [MAdCAM-1]), together with the prototypical arrest molecule, ICAM-1, mediate $T$ cell extravasation at sites of inflammation.

In light of the importance of the tissue-entry step to the overall efficacy of $\mathrm{CD}^{+} \mathrm{T}$ cell antitumor immunity, our studies focused on 2 fundamental issues: (a) examining the rate of homeostatic trafficking of $\mathrm{CD}^{+}$Teffs across tumor vessels embedded in a local inflammatory environment; and (b) determining whether the cytokinerich tumor microenvironment could be exploited therapeutically to improve delivery of cytotoxic $\mathrm{T}$ cells to tumor lesions. To investigate whether $\mathrm{CD}^{+}$Teff trafficking could be modified in tumor vessels, we examined the vascular response to cytokine-dependent inflammatory cues provided by systemic thermal therapy (STT) or LPS treatment. STT promotes IL-6-dependent trafficking of naive and central memory $\mathrm{CD}^{+}$and $\mathrm{CD}^{+} \mathrm{T}$ cells in HEVs $(12,15-17)$. LPS and its downstream mediators, TNF and IL-1 $\beta$, stimulate leukocyte adhesion in normal vessels, but do so to a much lesser extent in tumor vessels (18-21). STT also transiently decreases the number of circulating $T$ cells in mice and advanced cancer patients (16, 22). This raises the possibility that STT causes the redistribution of blood-borne $\mathrm{CD}^{+} \mathrm{T}$ cells to tumor destinations, as previously described for infiltration of innate cells (granulocytic and NK cells) in murine tumors and patient tumor xenografts $(23,24)$.

Here, we report that steady-state homing of $\mathrm{CD}^{+} \mathrm{Teffs}$ was limited in tumor microvessels, despite the presence of local inflammatory cytokines, and was not sufficient to support lysis of tumor cell targets. Tumor vessels underwent a switch to an adhesive vasculature supporting trafficking of $\mathrm{CD}^{+}$Teffs in response to STT but not LPS. Enhanced trafficking of $\mathrm{CD}^{+}$Teffs exclusively in tumor vessels after STT was mediated by a trans-signaling mechanism downstream of ligation of the gp130 signal-transducing receptor by IL- 6 and a soluble form of the IL- 6 receptor- $\alpha$ (sIL-6R). Our findings that early entry of $\mathrm{CD}^{+}$Teffs in tumor tissues led to apoptosis of tumor targets suggest that therapeutic targeting of the IL-6-enriched tumor microenvironment for $\mathrm{CD}^{+} \mathrm{T}$ cell trafficking may be an effective strategy to overcome immune evasion.

\section{Results}

Limited CD8 $8^{+}$Teff trafficking across tumor blood vessels is overcome by $S T T$. We initially used microscopic analysis to quantify infiltration of endogenous $\mathrm{CD}^{+} \mathrm{T}$ cells in the intratumoral regions of multiple murine solid tumor models. These included implantable subcutaneous tumors (colon tumor-26 [CT26], B16 melanoma, and ovalbumin-expressing B16 derivative [B16-OVA]) and latestage pancreatic islet tumors that develop at more than 26 weeks in the RIP-Tag5 transgenic model of de novo tumorigenesis (25). These tumors are characterized by a cytokine/chemokine-rich local inflammatory environment (e.g., TNF, IL-1 $\beta$, IL-6, VEGF, CCL2, CCL5, or CXCL10; Supplemental Figure 1A; supplemental material available online with this article; doi:10.1172/JCI44952DS1) (26). Baseline intratumoral infiltration by endogenous $\mathrm{CD}^{+}$ $\mathrm{T}$ cells was uniformly low in each tumor type (Figure 1A), consistent with reports that these tumors are not permissive to intensive $\mathrm{CD}^{+} \mathrm{T}$ cell accumulation $(9,27-29)$.
To determine whether infiltration of endogenous $\mathrm{CD}^{+} \mathrm{T}$ cells could be improved by acute inflammation, we treated tumor-bearing mice with STT (core temperature elevated to $39.5^{\circ} \mathrm{C} \pm 0.5^{\circ} \mathrm{C}$ for 6 hours) using a regimen that is optimal for increasing naive/ central memory $\mathrm{T}$ cell trafficking across HEVs in non-tumor-bearing mice (15-17). A marked increase in intratumoral $\mathrm{CD}^{+} \mathrm{T}$ cell infiltration was detected microscopically in each tumor type after STT (Figure 1A). Flow cytometric analysis of B16-OVA tumors confirmed that STT increased endogenous $\mathrm{CD}^{+} \mathrm{T}$ cell localization in tumors and that these cells were primarily effector/memory T cells (Tems; 90\%-95\% CD44hi; Figure 1B and data not shown). STT concomitantly lowered the number of $\mathrm{CD} 4^{+} \mathrm{CD} 25^{+} \mathrm{FoxP}^{+}$ tumor-infiltrating Tregs, substantially increasing the overall $\mathrm{CD}^{+}$ Tem/Treg ratio (Figure 1B). STT did not alter the number of tumor-infiltrating macrophages $\left(\mathrm{CD} 11 \mathrm{~b}^{+} \mathrm{Ly} 6 \mathrm{C}^{-} \mathrm{Ly} 6 \mathrm{G}^{-}\right)$, polymor-

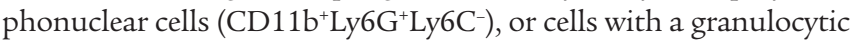

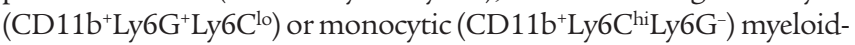
derived suppressor cell (MDSC) phenotype (Figure 1B). No change was detected in leukocyte subsets, including $\mathrm{CD}^{+} \mathrm{T}$ cells and Tregs at other sites, such as the spleen (Supplemental Figure 1B).

We performed short-term (1-hour) homing assays in CT26 or B16-OVA tumor-bearing mice to dissect the mechanisms underlying STT effects on $\mathrm{CD}^{+} \mathrm{T}$ cell infiltration. Quantification of fluorescently tagged $\mathrm{CD}^{+} \mathrm{T}$ cells in organs 1 hour after intravenous transfer enabled us to restrict the analysis to the multistep events that govern entry of blood-borne $T$ cells into tissues, since longer periods are required for additional processes that also affect overall infiltration (e.g., apoptosis, retention, proliferation, and egress). The rate of trafficking of adoptively transferred CD8 ${ }^{+}$ T cells was compared at 3 distinct vascular sites: HEVs of lymphoid organs, normal vessels of extralymphoid organs, and tumor vessels. Murine TK1 lymphoma CD8 ${ }^{+} \mathrm{T}$ cells or primary activated $\mathrm{CD}^{+} \mathrm{T}$ cells (from OVA-specific TCR transgenic OT-I mice or CT26 tumor-draining LNs) were used as indicator cells to determine the ability of vessels to support trafficking. These CD8 ${ }^{+}$ $T$ cells expressed the requisite homing receptors for recruitment to inflammatory sites (i.e., PSGL-1, E/P-selectin ligands, the ICAM-1 ligand lymphocyte function-associated antigen-1 [LFA-1 integrin], and CXCR3; Supplemental Figure 2A). Additionally, TK1 cells and a subpopulation of transferred primary $\mathrm{CD} 8^{+} \mathrm{T}$ cells expressed trafficking receptors necessary for entry across lymphoid organ HEVs (i.e., $\alpha 4 \beta 7$ integrin, L-selectin, CCR7, and LFA-1).

Low rates of homeostatic trafficking of adoptively transferred $\mathrm{CD}^{+} \mathrm{T}$ cells were detected across tumor vessels in short-term homing studies in normothermic (NT) control mice compared with HEVs of mesenteric LNs or Peyer patches (Figure 1, C and $\mathrm{D}$, and Supplemental Figure 2B, $P<0.0001)$. Moreover, $\mathrm{CD}^{+}$Teff homing in tumor vessels was only marginally higher than in normal vessels of extralymphoid organs (e.g., pancreas and kidney; $P<0.002)$. STT pretreatment increased homing of transferred $\mathrm{CD}^{+} \mathrm{T}$ cells at least 2 -fold across HEVs in tumor-bearing mice and increased trafficking across tumor vessels approximately 5 -fold, as determined by microscopic and flow cytometric analysis (Figure 1, C and D, and Supplemental Figure 2, B and C). In contrast, STT failed to alter $\mathrm{CD}^{+} \mathrm{T}$ cell entry across normal vessels of extralymphoid organs. The majority of fluorescently tagged $\mathrm{T}$ cells detected microscopically in tumor tissues (80\%-90\%) and lymphoid organs (70\%-85\%) extravasated outside CD $31^{+}$vessels, whereas less than $35 \%$ of cells were located in the parenchyma of other tissues (data not shown). STT did not appear to affect 
A

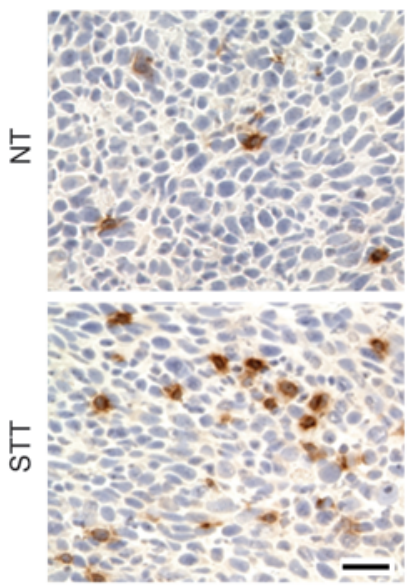

B16
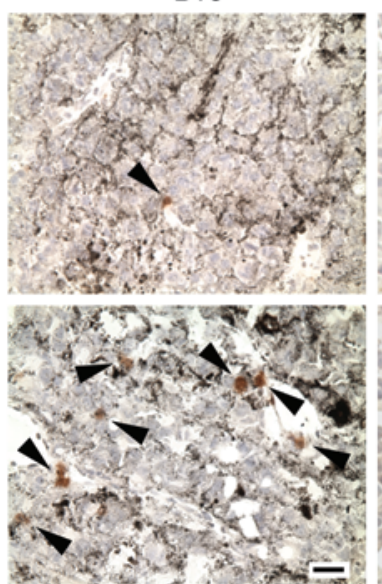

B

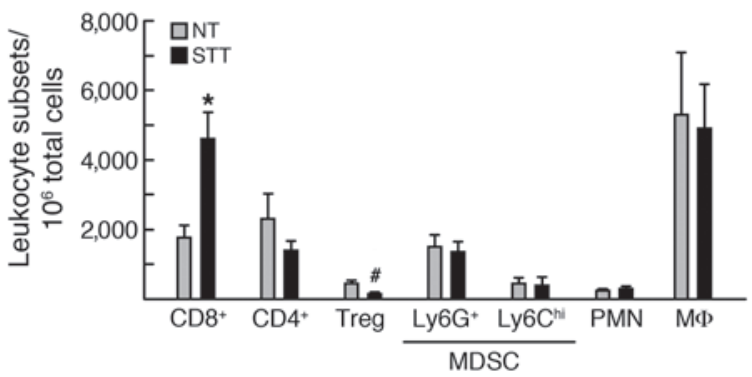

RIP-Tag5

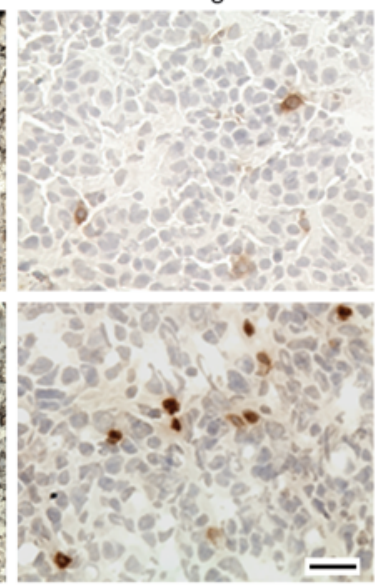

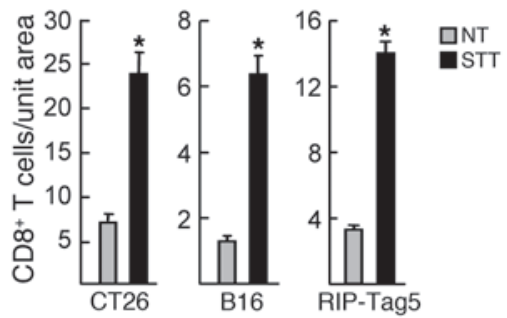

C
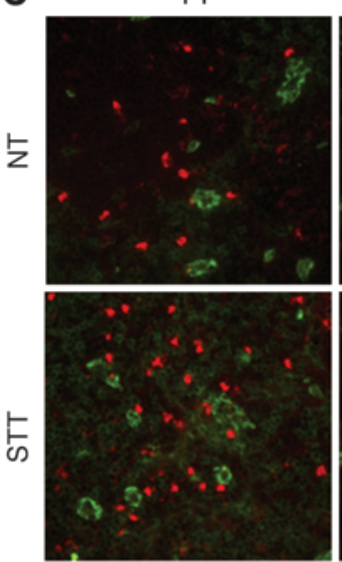

CT26 tumor

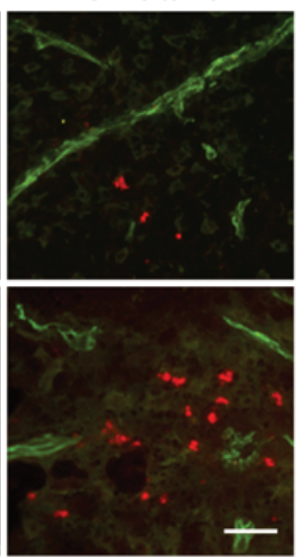

D OT-I T cells/B16-OVA
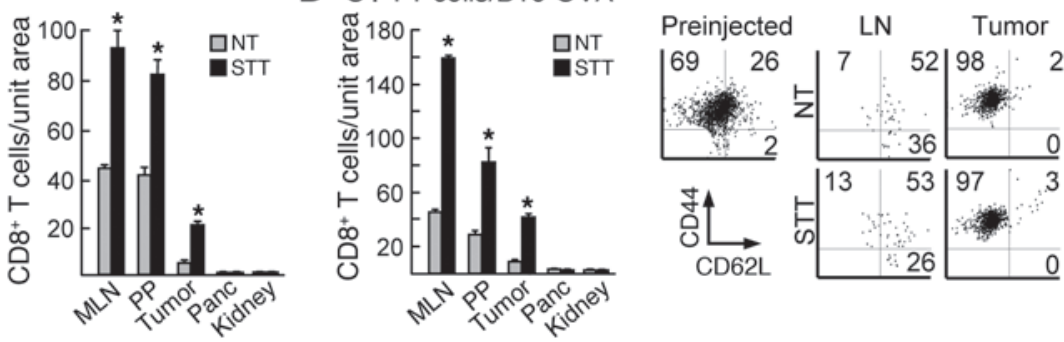

Figure 1

Homeostatic and thermally inducible trafficking of CD8 ${ }^{+}$T cells at organ sites in NT control and STT-treated mice. (A) Photomicrographs of immunostained endogenous CD8 ${ }^{+} \mathrm{T}$ cells (arrowheads denote CD8+ $\mathrm{T}$ cells in melanin+ $\mathrm{B} 16$ tumors), and quantification of CD8+ $\mathrm{T}$ cell infiltra-

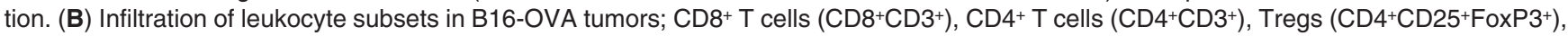
granulocytic MDSCs (CD11 b+Ly6G+Ly6Clo), monocytic MDSCs (CD11b+Ly6ChilLy6G-); polymorphonuclear cells (PMNs; CD11b+ Ly6G+ Ly6C-),

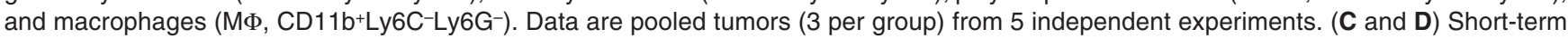
(1 hour) homing of TK1 cells (C) or activated OT-I T cells (D) to mesenteric LNs (MLNs), Peyer patches (PP), tumor, pancreas (Panc), and kidney. (C) Representative photomicrographs and quantification of TRITC-labeled TK1 CD8 ${ }^{+}$T cells (red) in tissues counterstained for CD31+ vessels (green). (D) Quantification of TRITC-labeled OT-I T cells in B16-OVA tumor-bearing mice by microscopy. Representative dot plots show the phenotype of TRITC-labeled OT-I T cells that trafficked into LNs and tumors. CD62L is L-selectin. Data are based on analysis of equivalent numbers of transferred CD8 ${ }^{+}$T cells in pooled samples $(n=3$ mice); numbers denote percent positive cells. $(\mathbf{A}, \mathbf{C}$, and $\mathbf{D})$ Data are representative of at least 3 independent experiments. ${ }^{\star} P<0.01,{ }^{\#} P<0.05$, NT versus STT. Scale bars: $100 \mu \mathrm{m}$. 
A
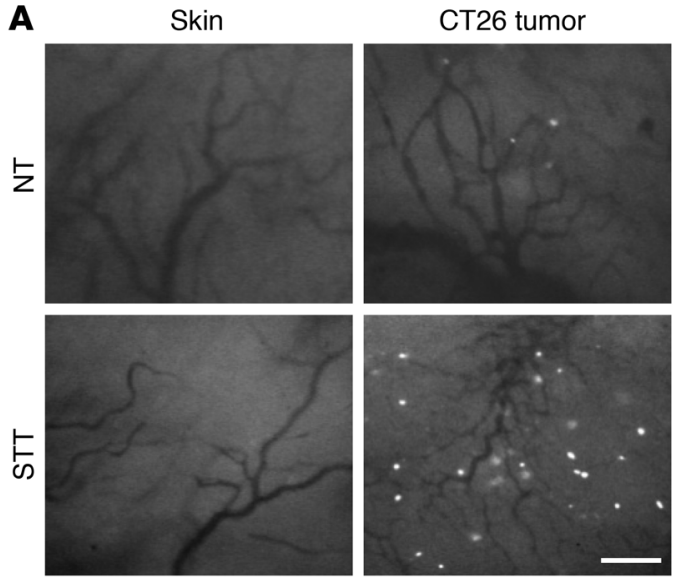

B

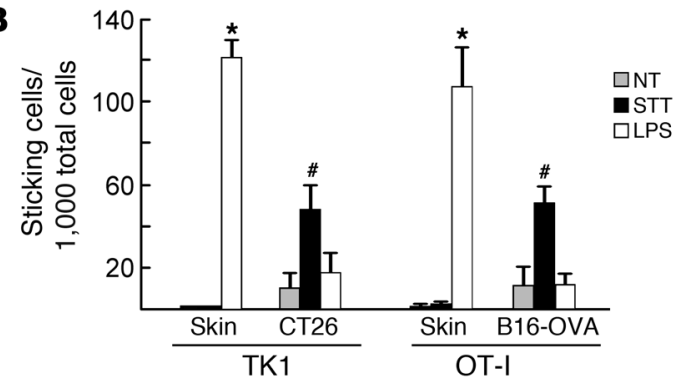

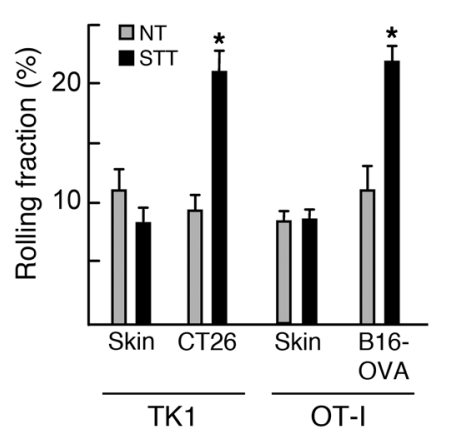

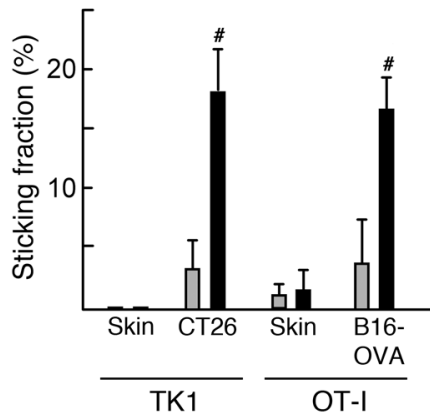

\section{Figure 2}

T cell-EC interactions in normal skin vessels and tumor vessels. (A) Representative images showing interactions between calcein-labeled TK1 CD8 ${ }^{+} \mathrm{T}$ cells and vessels. Rolling and sticking fractions of TK1 T cells and effector OT-I T cells in vessels are also shown. Scale bar: $100 \mu \mathrm{m}$. (B) Frequency of arrested T cells per 1,000 total cells. Data are from more than 3 independent experiments. ${ }^{*} P<0.001,{ }^{\sharp} P<0.04$ versus NT. There was no statistical difference between NT and LPS treatment groups in the tumor (CT26, $P<0.08$; B16-OVA, $P<0.4)$.

interstitial migration of extravasated $\mathrm{CD}^{+} \mathrm{T}$ cells, as determined by measuring the distance between fluorescently tagged cells and the nearest vessel, although the high vessel density may preclude conclusive assessment by immunohistochemical analysis (Supplemental Figure 2D). Tumor vessels were distinguished from HEVs by the type of $\mathrm{CD}^{+} \mathrm{T}$ cell population that trafficked in NT or STT-treated mice (Figure 1D). Substantial enrichment for naive (L-selectin ${ }^{\text {hi }} \mathrm{CD} 44^{\mathrm{lo}}$ ) and central memory (L-selectin ${ }^{\text {hi }}$ CD $44^{\mathrm{hi}}$ ) $\mathrm{CD}^{+} \mathrm{T}$ cells was observed after extravasation via HEVs, whereas cells that trafficked across tumor vessels were almost exclusively $\mathrm{CD}^{+}$Tems (L-selectin ${ }^{\text {lo }} \mathrm{CD} 44^{\mathrm{hi}}$ ).

We used epifluorescence intravital microscopy to directly image the multistep interactions necessary for extravasation of $\mathrm{CD}^{+}$Teffs within normal and tumor vessels in real time. During homeostasis, comparably low proportions of activated CD8 ${ }^{+}$ $\mathrm{T}$ cells $(\sim 10 \%)$ initiated rolling in tumor vessels and normal vessels in dorsal skin flap window chambers (Figure 2A and Supplemental Video 1). Moreover, the fraction of rolling cells that transitioned to firm arrest was minimal $(<5 \%)$ at both vascular sites. STT induced an approximately 2 -fold increase in $\mathrm{T}$ cell rolling and an approximately 5 -fold increase in firm arrest in tumor vessels, whereas adhesion was unaltered in normal vessels (Figure 2A and Supplemental Video 2). In contradistinction to STT, systemic administration of the potent TLR4 agonist LPS strongly increased the overall frequency of $\mathrm{CD}^{+} \mathrm{T}$ cells that arrested in normal vessels, but did not significantly improve adhesion in the tumor vasculature (Figure 2B). Vascular parameters (vessel diameter, blood cell velocity, and wall shear rate) were similar in control and treated mice during the observation period (Supplemental Figure 3). Thus, we attribute thermally induced lymphocyte-endothelial interactions in tumor vessels to stable changes in adhesion in the intravascular space rather than to altered hemodynamics. Collectively, these findings indicated that constitutive trafficking of $\mathrm{CD}^{+}$Teffs across tumor vessels was limited, providing a potential mechanism for immune evasion. The results further demonstrated that tumor vessels were uniquely predisposed to support enhanced CD8 ${ }^{+}$Teff trafficking in response to inflammatory cues provided by STT.

STT-induced $C D 8^{+}$Teff homing in the tumor microenvironment is dependent on E/P-selectin and ICAM-1. The requirement for individual trafficking molecules during $\mathrm{CD}^{+} \mathrm{T}$ cell binding to tumor vessels was probed using neutralizing antibodies or pertussis toxin (PTX), which disrupts $G$ protein-coupled chemokine receptor-mediated signaling. Inhibition of E/P-selectin, ICAM-1, or chemokine receptor signaling did not significantly affect vascular hemodynamics (data not shown), homeostatic rolling, or firm arrest of $\mathrm{CD}^{+}$ $\mathrm{T}$ cells in CT26 tumor vessels (Figure 3A and Supplemental Videos 3-5). Combined functional blockade of E/P-selectin abrogated STT-induced $\mathrm{CD}^{+} \mathrm{T}$ cell rolling interactions, while the proportion of residual rolling cells that transitioned to firm arrest was not affected. PTX exclusively blocked T cell transition to firm arrest, consistent with the requirement for chemokine activation of integrin-dependent firm adhesion by T cells (14). Neutralizing antibody specific for ICAM-1 (i.e., ligand for LFA-1 integrin) similarly reduced the proportion of $\mathrm{CD}^{+} \mathrm{T}$ cells that transitioned to firm sticking without altering the rolling frequency. ICAM-1 blocking antibody also inhibited $\mathrm{CD}^{+}$Teff extravasation in short-term homing assays (Figure 3B). Intravascular adhesion was not affected by treatment of $\mathrm{CD}^{+} \mathrm{T}$ cells with an $\alpha 4 \beta 7$ integrin functionblocking antibody (DAKT32) that prevents binding to VCAM-1 and MAdCAM-1 (ref. 30 and Figure 3A), which indicates that these vascular ligands do not contribute to trafficking in subcutaneous tumor vessels during thermally induced inflammation. 

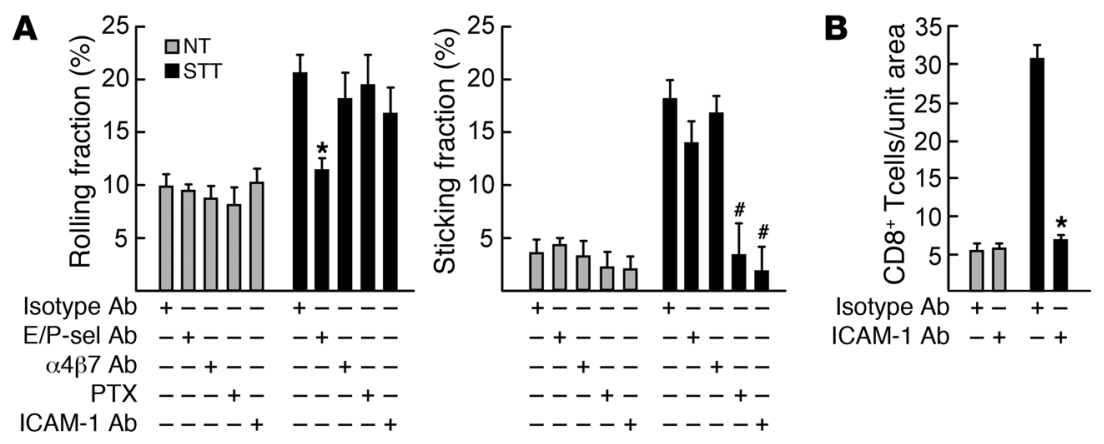

\section{Figure 3}

Contributions of trafficking molecules to $\mathrm{CD}^{+} \mathrm{T}$ cell extravasation. Determination of rolling fractions and sticking fractions by intravital microscopy (A) or short-term (1 hour) homing (B) of fluorescently tagged TK1 CD8 ${ }^{+}$T cells in CT26 tumors after treatment with functionblocking reagents (i.e., antibodies or PTX). Data are pooled from 3 independent experiments $(\mathbf{A})$ or are representative of at least 3 independent experiments (B). ${ }^{*} P<0.001$, $\# P<0.05$ versus control antibody.

ICAM-1 upregulation on vessels is considered a signature of inflammation based on the ability to direct leukocyte trafficking to sites throughout the body (14). Therefore, we examined the relative intravascular density of ICAM- 1 on $\mathrm{CD} 31^{+}$tumor vascular endothelium. Homeostatic expression of ICAM-1 was low on intratumoral vessels of RIP-Tag5, CT26, and B16-OVA tumors (Figure 4). STT substantially increased the intravascular expression of ICAM-1 in tumor vessels, whereas the density of CD31 or another LFA-1 ligand, ICAM-2, was unchanged (Figure 4 and Supplemental Figure 4A). ICAM-1 induction also occurred in subcutaneous EMT6 mammary tumors as well as in B16 tumors seeded in the lung in a model of end-stage metastasis (Supplemental Figure 4B and data not shown). Results in RIP-Tag5 transgenic mice underscore the highly localized nature of the vascular response to STT, since ICAM-1 was not induced in vessels of histologically normal islets in close proximity to islet tumors (Figure 4A). Overall, these findings suggest that low constitutive emigration of $\mathrm{CD}^{+}$Teffs into the tumor microenvironment is attributed to limited availability of trafficking molecules in tumor vessels.

Prior studies have shown that infiltration of $\mathrm{CD}^{+}$Teffs in a subcutaneous EG7-thymoma model analyzed 3 days after adoptive transfer of OT-I cells occurs preferentially in the tumor periphery $(11,31)$. Thus, a possible limitation to adoptive cell therapy is that cytotoxic destruction of tumor cells is initially confined to the peripheral rim, allowing time for escape mechanisms to be enacted in central regions. To determine if the access of blood-borne $\mathrm{CD}^{+}$ $\mathrm{T}$ cells to tumor tissues after STT was restricted to a specific subregion, we quantified ICAM- 1 expression and $\mathrm{CD}^{+} \mathrm{T}$ cell homing 1 hour after transfer in defined regions of tumor sectors of CT26 and B16-OVA solid tumors. Basal homing was statistically lower in the tumor center than in the peripheral region $(P<0.002)$, although ICAM-1 and CD31 expression was equivalent in both regions (Figure 4C and data not shown). STT dually increased intravascular ICAM-1 expression and homing of adoptively transferred $\mathrm{CD}^{+}$Teffs in both the tumor center and the periphery.

IL-6 trans-signaling promotes $C D 8^{+} T$ cell homing. We used a cytokineblocking strategy to pinpoint the contribution of candidate inflammatory cytokines that could potentially promote trafficking within the tumor microenvironment. IL- 6 neutralizing anti- body prevented thermal induction of ICAM-1 on vessels of spontaneous and implantable tumors, whereas neutralization of TNF, IL-1 $\beta$, or IFN- $\gamma$, either individually (Figure 5A and Supplemental Figure 5, A and B) or in combination (data not shown), was ineffective. IL-6-dependent induction of ICAM-1 during STT was accompanied by upregulation of the signal transducing subunit of the IL- 6 family receptor, gp130, on tumor vessels (Figure 5B). Thermal induction of ICAM-1 and intratumoral localization of endogenous $\mathrm{CD}^{+} \mathrm{T}$ cells were further shown to be blocked by recombinant soluble gp130 (sgp130; Figure 5A and Supplemental Figure 5, A and C), in parallel to our prior findings for HEVs $(12,15)$. sgp130 selectively antagonizes trans-signaling initiated by ligation of transmembrane gp130 by sIL-6R, without interfering with classical signaling by membrane-anchored IL-6R (32). Intravital imaging revealed that IL- 6 trans-signaling was required for both $\mathrm{E} / \mathrm{P}$-selectin-mediated rolling interactions and ICAM-1-dependent firm arrest of $\mathrm{CD}^{+} \mathrm{T}$ cells in tumor vessels after STT (Figure 5C). Paradoxically, we were able to detect constitutive IL- 6 trans-signaling activity that supported B16-OVA and CT26 tumor growth (Figure 5D and data not shown) in the face of low baseline $\mathrm{T}$ cell trafficking in the same local microenvironment. These results are consistent with the tumor-promoting activity reported for IL-6 in multiple tumor systems $(1,2)$.

The sensitivity of tumor vessels to IL- 6 trans-signaling was confirmed by a gain-of-function approach. Intravenous administration of recombinant hyper-IL-6 (H-IL-6) fusion protein composed of IL-6 and sIL-6R (33) activated the canonical IL-6-responsive transcription factor STAT3 in murine tumor vascular ECs, as indicated by nuclear localization of phosphorylated STAT3 (pSTAT3) after treatment (Figure 6A). H-IL-6 mirrored endogenous IL-6 trans-signaling activity during STT with respect to induction of $\mathrm{CD}^{+}$Teff tethering/rolling and firm arrest as well as upregulation of ICAM-1 density in murine tumor vessels (Figure 6B). Analysis of the effects of H-IL- 6 on vascular expression of ICAM- 1 was further extended to stage IV colorectal patient tumor explants. Baseline ICAM-1 density was low on intratumoral vessels in 3 of 3 patient tumor biopsies examined, despite the presence of IL-6 in tumor lesions (Figure 6C). H-IL- 6 treatment markedly increased ICAM-1 density on CD $31^{+}$ vessels in 2 of 3 patient tumor explants. The absence of response in tumor explants of a third patient could reflect a refractory state of tumor ECs, negative regulatory factors, or the quality of tissue with comparatively high fat content that could affect perfusion by recombinant cytokine. Taken together, these data suggest that IL-6 trans-signaling pathways are not constitutively operative in promoting adhesion in mouse or human tumor vascular endothelium and that IL- 6 trans-signaling has the potential to upregulate the biosynthesis of ICAM-1 in tumor vessels.

We exploited the fact that B16 tumor cells do not produce detectable amounts of IL-6 in vitro, as previously described (34) and confirmed by Luminex (data not shown), in order to determine whether cytokine production by stromal cells in the local microenvironment contributes to T cell trafficking. IL- 6 was detectable in B16 tumor extracts after implantation in WT but not $\mathrm{Il6}^{-/-}$mice (Figure 7A), consistent with local stromal cells providing IL-6 in 
A
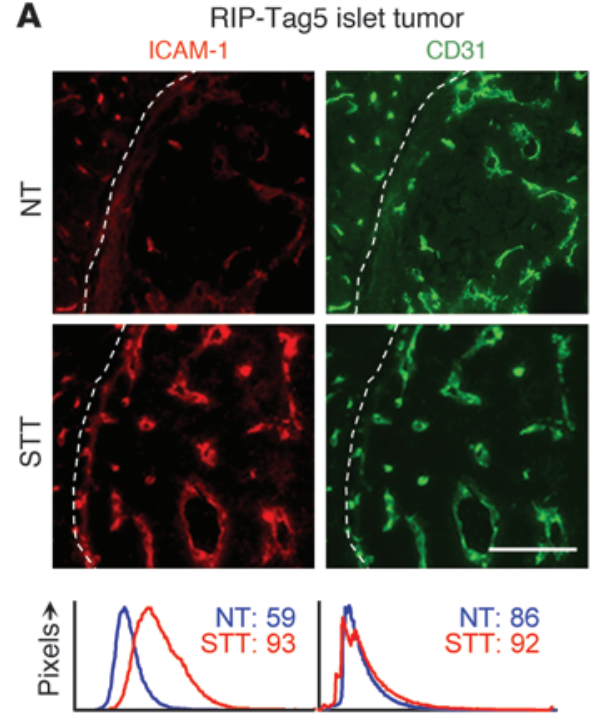

Fluorescence $\longrightarrow$

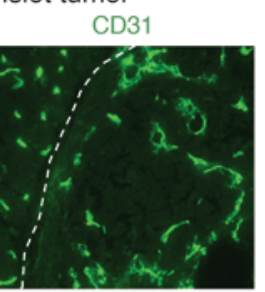

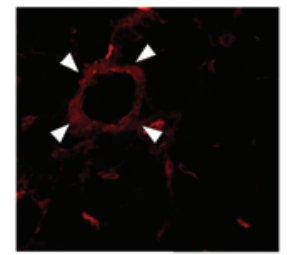
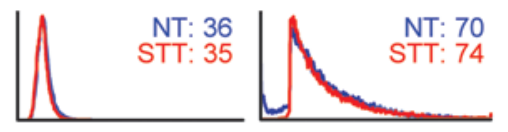
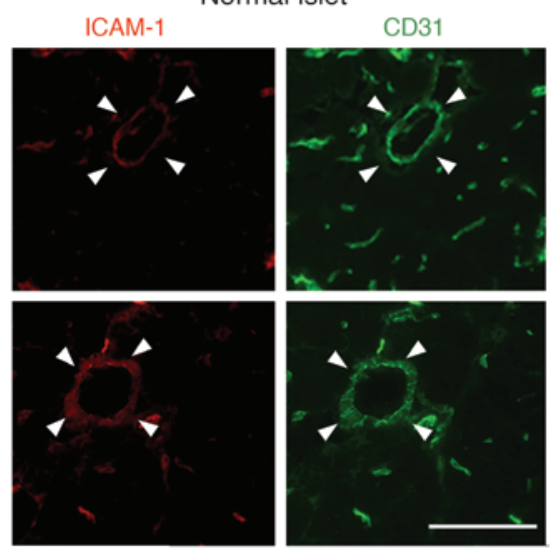

B
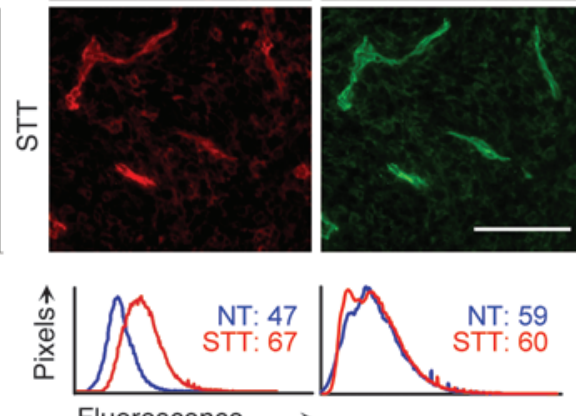

CT26
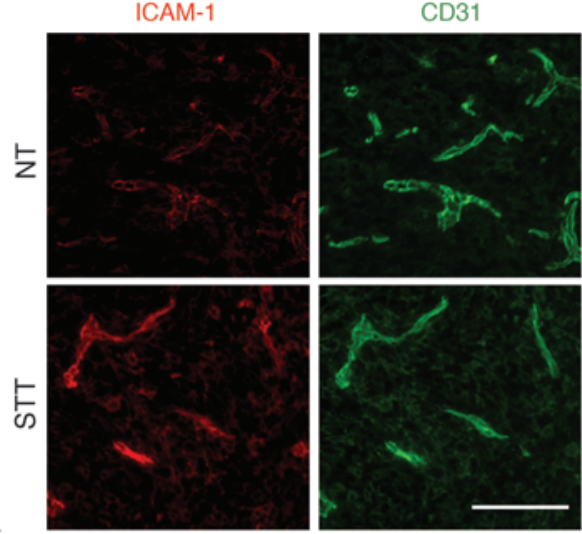

Fluorescence $\longrightarrow$

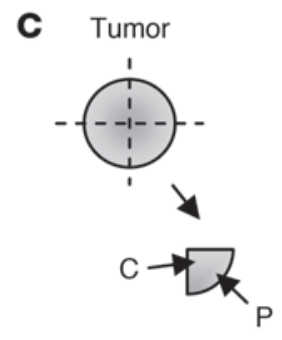

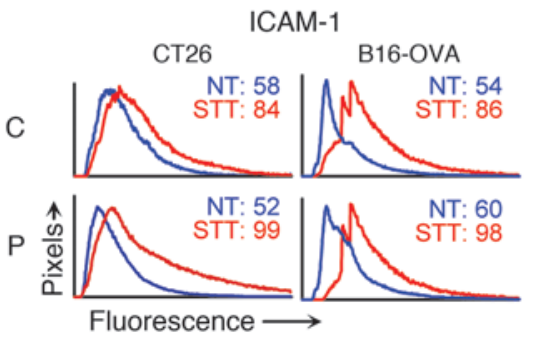

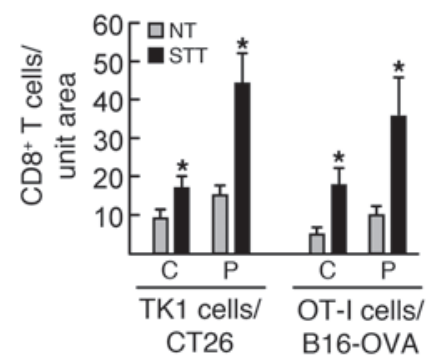

Figure 4

Thermal induction of ICAM-1 in tumor vessels. Intravascular staining of ICAM-1 in pancreata from RIP-Tag5 mice (A) and CT26 tumors (B) by intravenous injection of anti-ICAM-1 antibody. Tissue sections were stained with TRITC-conjugated secondary antibody (red) and counterstained with anti-CD31 antibody (green) to visualize vascular structures. Dotted lines indicate tumor boundary; arrowheads indicate normal pancreatic islets of RIP-Tag5 mice. Scale bars: $100 \mu \mathrm{m}$. (C) Expression of vascular ICAM-1 and CD8 ${ }^{+}$T cells trafficking in the center (C) and periphery (P) of CT26 and B16-OVA tumors. Histograms depict quantification of immunofluorescence intensity of ICAM-1 or CD31 in all CD31+ vessels; numbers denote MFI. Bar graphs depict CD8 ${ }^{+}$T cell infiltration. All data are representative of at least 3 independent experiments. ${ }^{*} P<0.05$ versus NT.

this system. After STT treatment, strong induction of intravascular ICAM-1 was detected in B16 tumor vessels in WT but not $I l 6^{-/-}$mice, correlating with increased recruitment of endogenous $\mathrm{CD}^{+} \mathrm{T}$ cells (Figure 7, B and C). A trend toward increased IL- 6 was detected after STT in tumor extracts from WT mice, although the results did not reach statistical significance (Figure 7A). Reciprocal bone marrow chimera experiments further demonstrated that radiation-resistant nonhematopoietic stromal cells were the primary source of IL- 6 that promotes ICAM-1-dependent trafficking of CD8 ${ }^{+}$Teffs across tumor microvascular checkpoints during STT. ICAM-1 induction in B16 tumor vessels did not occur when IL-6 was deficient in nonhematopoietic stromal cells (i.e., WT bone marrow introduced into lethally irradiated IL-6-deficient hosts; $\left.\mathrm{WT} \rightarrow I l 6^{--}\right)$, whereas ICAM-1 induction occurred normally if IL-6 was deficient in bone marrow-derived hematopoietic cells ( Il $^{-/-} \rightarrow$ WT; Figure 7D). These results were unexpected, given reports that hematopoietic cells are major suppliers of IL-6 within the local environment during tumor progression $(1,2)$. Collectively, these findings demonstrate a nonredundant role for transient IL- 6 trans-signaling in promoting inflammation-induced $\mathrm{CD} 8^{+} \mathrm{T}$ cell trafficking in tumors.
Causal link between $\mathrm{CD}^{+} T$ cell homing and tumor apoptosis. Our findings supported a scenario in which limited trafficking of $\mathrm{CD}^{+}$ Teffs to the tumor microenvironment can be overcome through an IL-6 trans-signaling mechanism. These observations would predict that antitumor immunity could be boosted if adoptive transfer of tumor-reactive $\mathrm{CD}^{+}$Teffs was performed immediately after STT to take advantage of the induction of trafficking molecules on intratumoral vessels. We tested this hypothesis in the highly aggressive, orthotopic B16-OVA melanoma system in which an octapeptide of chicken OVA (SIINFEKL) serves as a surrogate tumor antigen. Tumors were implanted 3, 7, or 14 days prior to treatments, and subcurative doses of OVA-specific cytotoxic OT-I CD8 ${ }^{+} \mathrm{T}$ cells were used for adoptive transfer in order to discriminate the contribution of trafficking to antitumor immunity. Pilot studies confirmed that early (3 day) tumors contained vascular networks that could serve as conduits for trafficking and that ICAM-1 was inducible on these vessels by STT (Supplemental Figure 6A). B16-OVA tumor growth was unaltered in NT mice (Figure 8A), despite substantial expansion of the circulating pool of tumor-specific $\mathrm{CD}^{+} \mathrm{T}$ cells as a result of bolus infusion of effector OT-I cells (Supplemental Figure 6B). Significant growth delays and prolonged survival were 
A
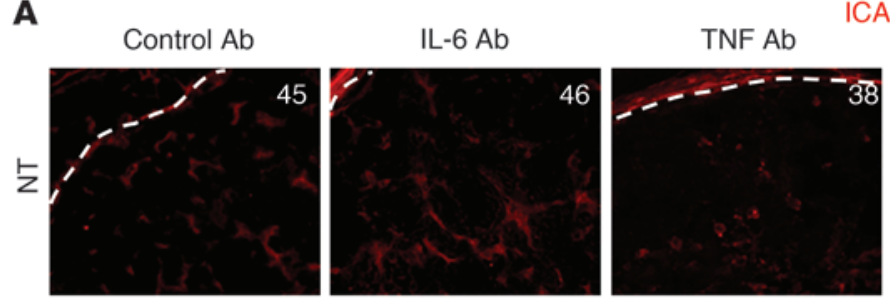

ICAM-1
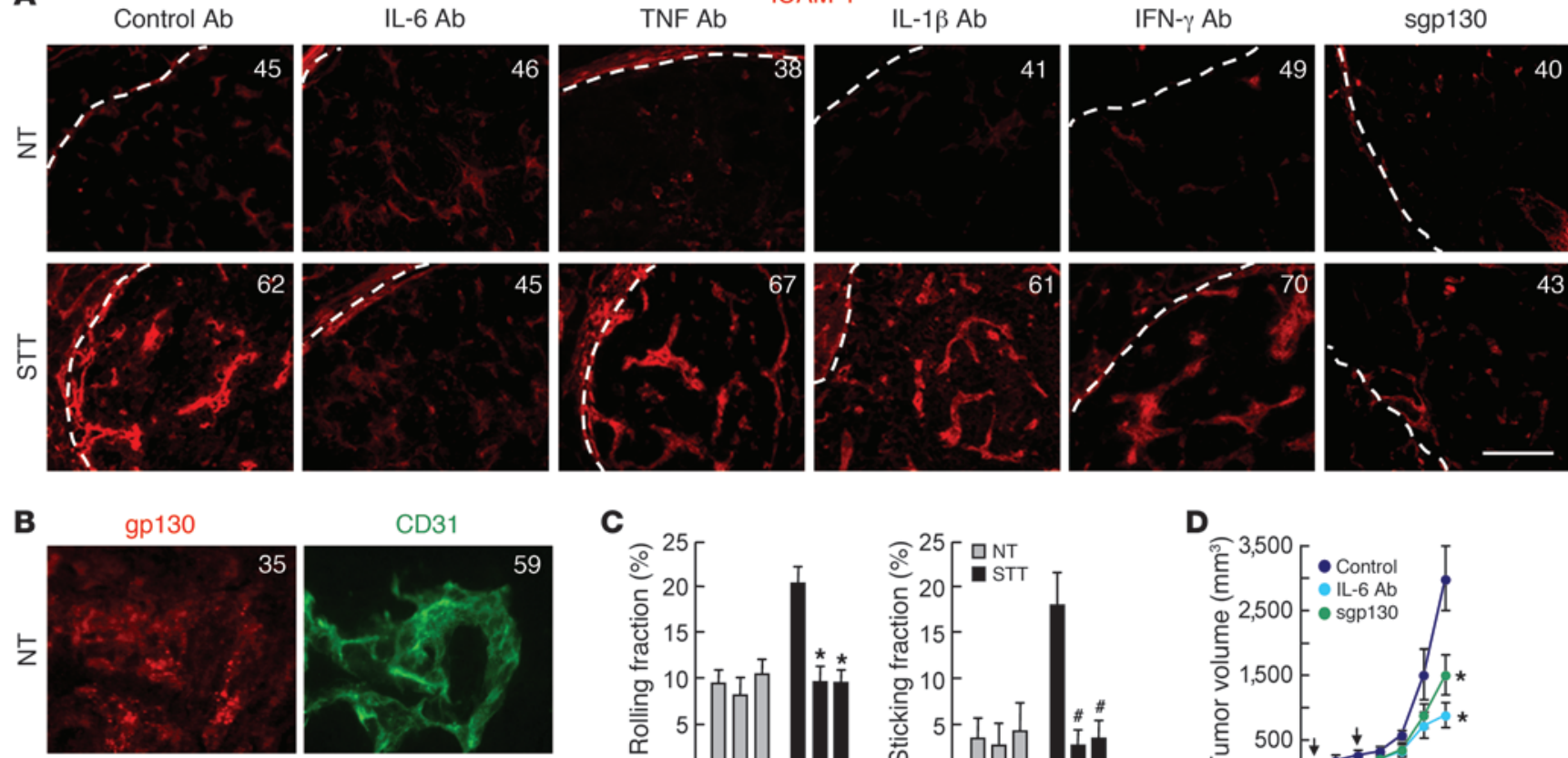

C
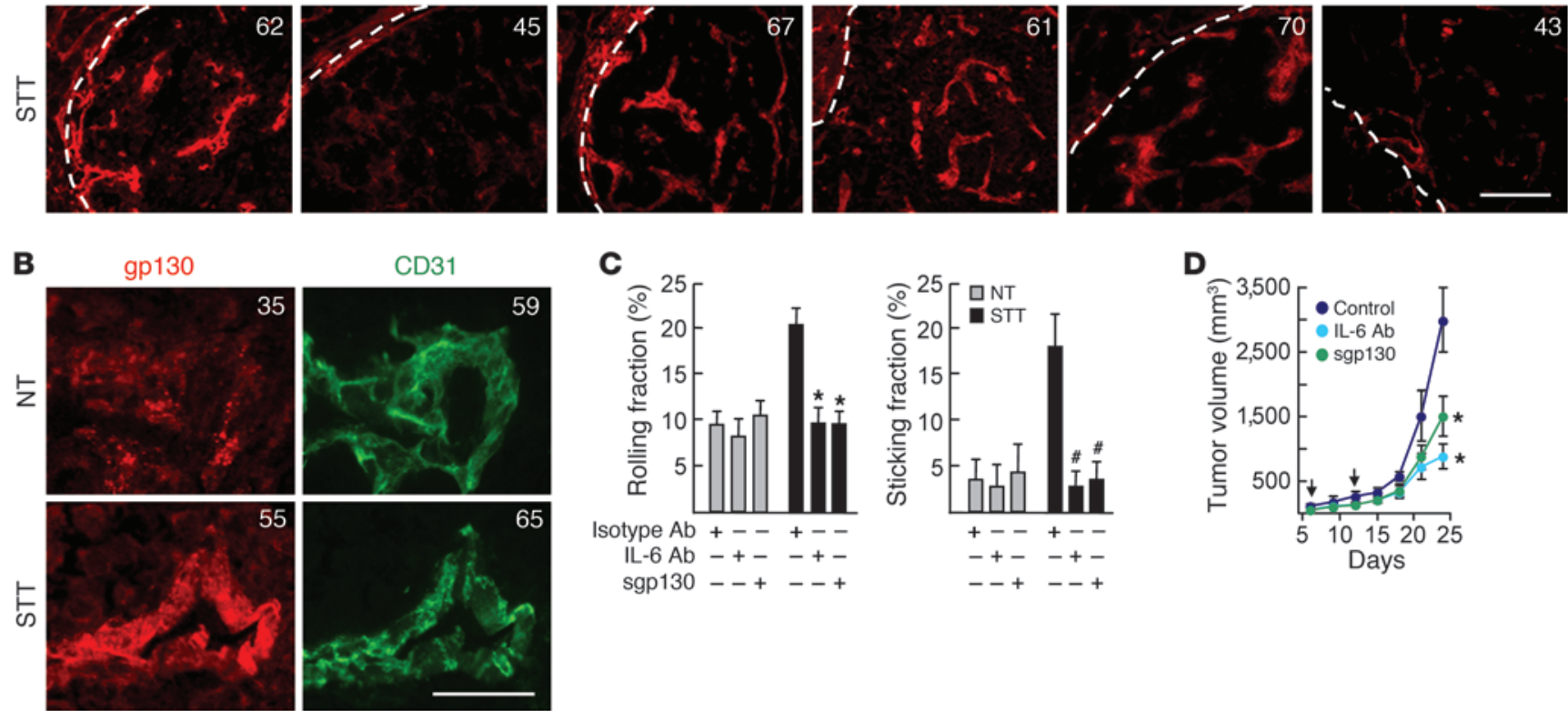

\section{Figure 5}

IL-6 trans-signaling mediates thermal stimulation of ICAM-1 and CD8+ T cell trafficking. (A) Cytokine neutralizing antibody, isotype-matched control antibody, or recombinant sgp130 was administered intravenously in RIP-Tag5 mice 30 minutes before STT. Immunofluorescence staining of ICAM-1 (red) was performed in pancreatic cryosections. Photomicrographs depict representative regions. Dotted lines indicate tumor boundary; numbers denote MFI of ICAM-1 staining on all CD31+ vessels. Scale bar: $100 \mu \mathrm{m}$. (B) Representative photomicrographs showing thermal induction of gp130 (red) on CD31+ (green) B16-OVA tumor vessels. Numbers denote MFI of gp130 or CD31 staining on CD31+ vessels. Scale bar: $50 \mu \mathrm{m}$. (C) Rolling and sticking fractions of calcein-labeled TK1 CD8 ${ }^{+}$T cells in CT26 tumor vessels. $n=3$ independent experiments. ${ }^{*} P<0.001$, $\# P<0.03$ versus control. (D) Growth of B16-OVA tumors in NT mice measured after administration of IL-6 neutralizing antibody or sgp130 (arrows). Data are for at least 6 mice/group. ${ }^{*} P<0.04$ versus isotype control.

observed in WT recipient mice when OT-I cells were transferred immediately after STT, whereas STT alone had no effect on tumor progression (Figure 8A and Supplemental Figure 6C). Restrictions on B16-OVA tumor growth were not observed when STT and adoptive transfer of OT-I cells were performed in $\mathrm{Il6}^{-/-}$mice (Figure 8A and Supplemental Figure 6C). For studies in $\mathrm{Il}^{-/-}$mice, treatments were initiated on day 14 , when tumor size approximated that of 7 -day tumors of WT mice, since overall tumor growth lagged in an IL-6-deficient microenvironment. Substitution of STT by recombinant H-IL-6 in WT mice also enhanced the efficacy of adoptive cell transfer therapy (Supplemental Figure 6D). Improved tumor control was additionally detected in CT26 tumors expressing hemagglutinin as a surrogate tumor antigen after combined STT and adoptive transfer of HA-specific TCR transgenic clone $4 \mathrm{CD}^{+}$Teffs (Supplemental Figure 6E). Despite initial delays in growth of B16OVA and CT26-HA tumors, progression was eventually detected in all treatment groups, and long-term cures were not observed (Supplemental Figure 6, C-E).

We next addressed whether early trafficking of OT-I T cells in response to STT was associated with antigen-restricted killing in established (7 day) B16-OVA tumors. Equivalent increases in fluorescently tagged OT-I cells were detected in B16-OVA and parental B16 tumors at 1 hour after adoptive transfer (Figure 8B), which indicates that extravasation of $\mathrm{CD}^{+} \mathrm{T}$ cells was not antigen restricted. The majority of OT-I Tems (L-selectin ${ }^{\text {lo }}$ /P-selectin ligand ${ }^{\text {hi }}$ CD $44^{\text {hi }}$ LFA $-1{ }^{\text {hi }}$ CXCR $3{ }^{+}$) that homed to tumors expressed effector molecules, including granzyme B and IFN- $\gamma$ (Supplemental Figure 7). Elevated numbers of effector OT-I cells were maintained for 12 hours in B16-OVA tumors, whereas a partial decrease was detected in parental B16 tumors (Figure 8B). These differences are likely caused by egress of $\mathrm{CD}^{+} \mathrm{T}$ cells not engaged in antigen-specific interactions rather than by apoptosis in situ, since less than $5 \%$ of OT-I cells were TUNEL ${ }^{+}$within tumors (data not shown). The number of TUNEL ${ }^{+}$apoptotic cells within tumors was not altered 1 hour after $\mathrm{T}$ cell transfer (Figure 8B), in line with prior observations that it takes approximately 6 hours for individual tumor cells to be killed by cytotoxic T cells in vivo (31). STT treatment and subsequent adoptive transfer of OT-I cells increased the number of apoptotic cells detected at 12 hours in B16-OVA tumors, but not parental B16 tumors, which confirmed that 
A

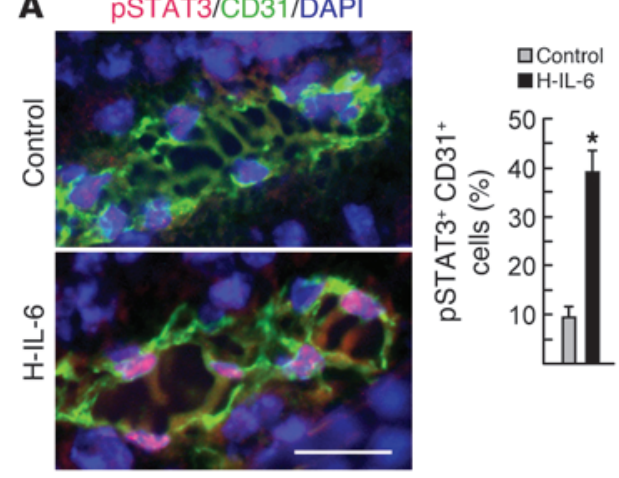

B

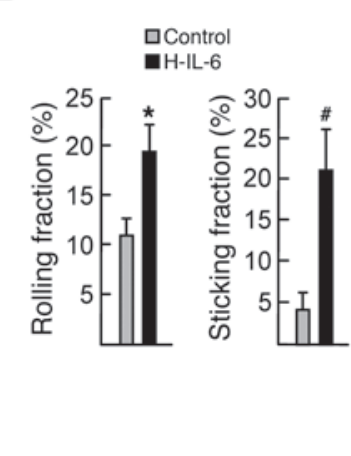

ICAM-1

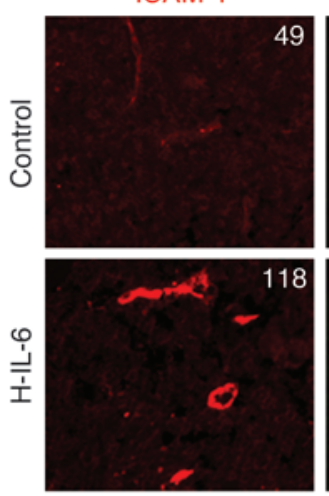

CD31

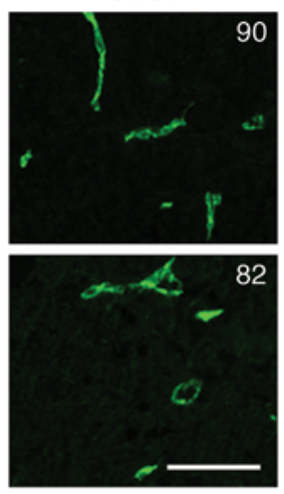

C

P1

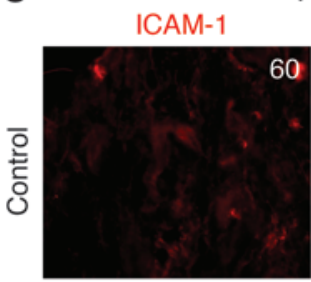

CD31
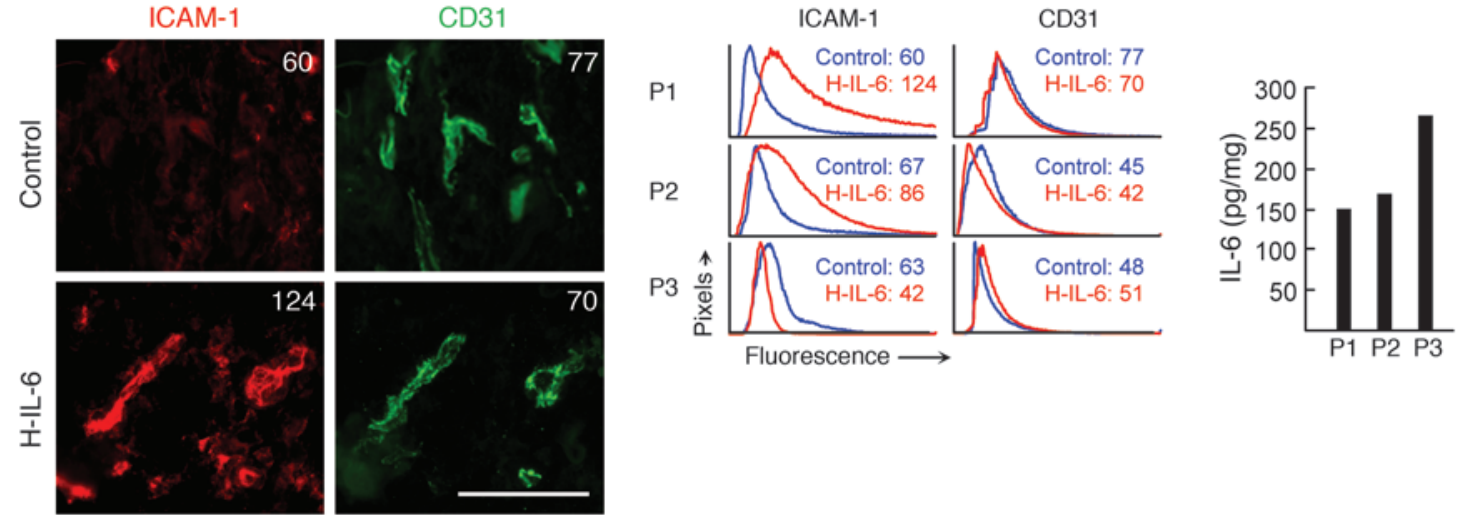

\section{Figure 6}

Vascular response to H-IL-6 in murine and patient tumors. (A) Immunofluorescence staining of pSTAT3 (red) in CD31+ (green) B16-OVA tumor vessels 15 minutes after intravenous administration of H-IL-6 fusion protein. Nuclei were stained with DAPI (blue). Microscopic quantification of pSTAT3 staining in CD31+ ECs is also shown; data are representative of 3 independent experiments. Scale bar: $50 \mu \mathrm{m}$. ${ }^{*} P<0.001$ versus control. (B) OT-I interactions with B16-OVA tumor vessels 6 hours after H-IL-6 treatment; data are from 3 independent experiments. Intravascular staining of ICAM-1 (red) on CD31+ (green) B16-OVA tumor vessels 6 hours after H-IL-6 treatment is also shown. Scale bar: $100 \mu \mathrm{m}$. ${ }^{*} P<0.001$, $\# P<0.03$ versus control. (C) Representative photomicrographs of immunofluorescence staining of ICAM-1 on CD $31^{+}$vessels in tumor explants of patient 1 (P1) after treatment with H-IL-6 for 6 hours. ICAM-1 and CD31 expression in 3 patient tumor explants is shown by histograms representing quantitative image analysis of the immunofluorescence intensity of adhesion molecules in CD31+vessels. Numbers in photomicrographs and histograms are MFI. IL-6 concentration in patient tumor explants is also shown. Scale bar: $100 \mu \mathrm{m}$.

cytolysis was antigen restricted. Notably, the number of apoptotic cells detected in B16-OVA tumors at 12 hours in NT mice was not above baseline despite bolus infusion of OT-I cells. These results suggest that homeostatic trafficking of $\mathrm{CD}^{+}$Teffs is not sufficient to achieve the requisite effector/target cell ratios necessary for cytolysis in situ.

We used 3 independent approaches to establish a cause-andeffect relationship between early trafficking mechanisms and apoptosis of tumor targets (Figure 8C). First, after determining that transient blockade of IL-6 activity did not directly influence tumor cell viability during the 12 -hour observation period, we used IL-6 neutralizing antibody to inhibit discrete steps in the recruitment process (i.e., E/P-selectin-dependent rolling and ICAM-1mediated firm arrest). Second, we used E/P-selectin-specific antibody to selectively block rolling interactions. Finally, we used a genetic approach involving Icam $1^{-/-}$mice in order to block firm arrest in vessels and transendothelial migration without interfering with ICAM-1 requirements during contact-dependent cytolysis of tumor targets. Blockade of OT-I cell trafficking by each strategy diminished the number of apoptotic cells detected in tumors of mice treated with STT. Taken together, these findings suggest a model in which the antitumor activity of $\mathrm{CD}^{+} \mathrm{Teffs}$ is predicated on the rate of trafficking across tumor vascular gateways, which can be promoted by local IL-6 trans-signaling (Figure 9).

\section{Discussion}

Tumor immunity requires systemic activation of tumor-specific $\mathrm{CD}^{+}$Teffs as well as their site-specific delivery into tumors to efficiently kill tumor targets. Numerous immunosuppressive mechanisms have been documented that inhibit $T$ cell priming in tumordraining LNs during the initiation phase, thereby limiting the number of tumor-reactive CD8 ${ }^{+}$Teffs deployed into circulation (35). The present study was undertaken to determine whether constraints on homeostatic trafficking of $\mathrm{CD}^{+} \mathrm{T}$ cells across tumor vessels during the effector phase are an additional impediment to tumor immunity. Our experimental design bypassed the initiation phase by using adoptively transferred $\mathrm{CD}^{+}$Teffs to interrogate the binding activity of tumor vessels in situ. 
A
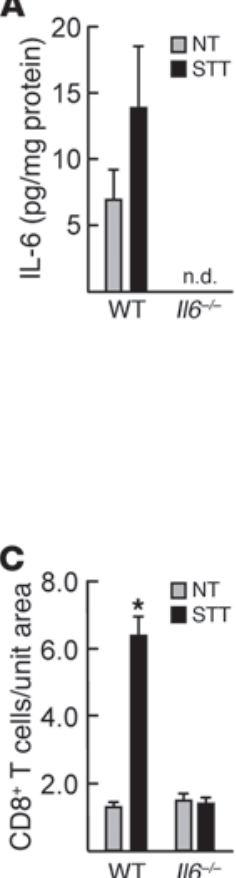

B

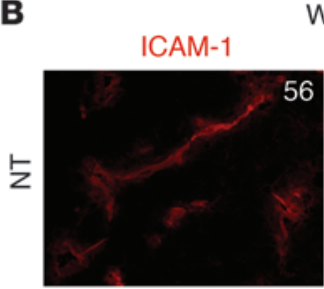

WT
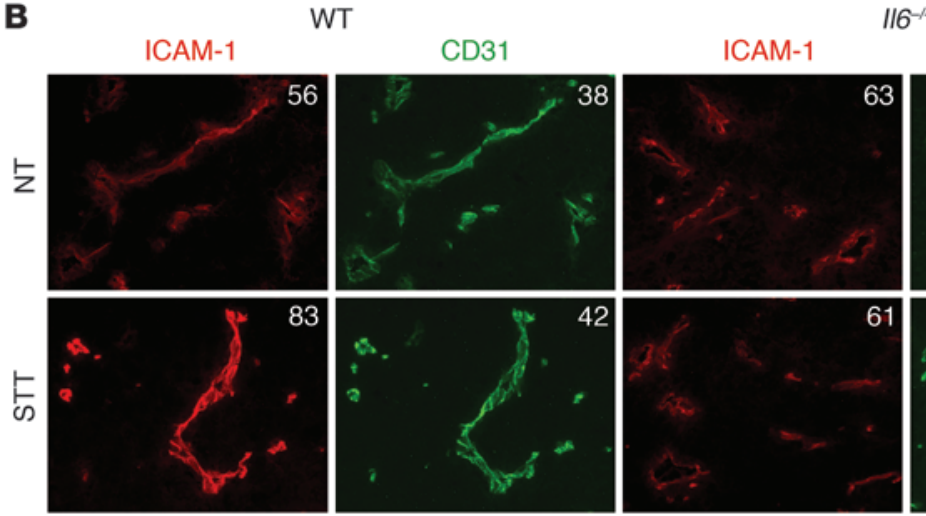

$116^{-1-}$

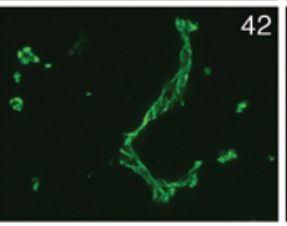

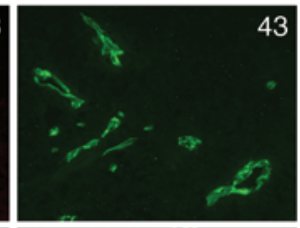

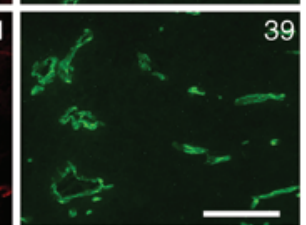

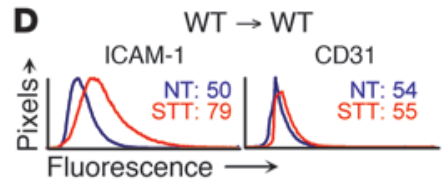
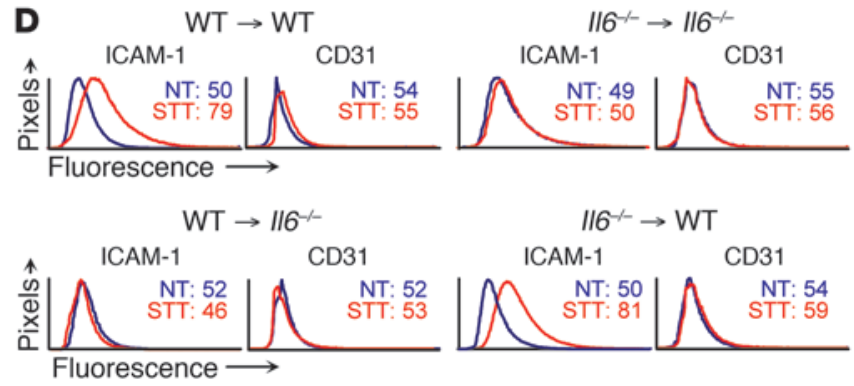

\section{Figure 7}

Nonhematopoietic stromal cell-derived IL-6 induces vascular ICAM-1 expression in the tumor microenvironment. (A) IL-6 concentration in B16 tumor lysates from NT control or STT-treated WT and $I / 6^{-/-}$mice, determined by Luminex. Data are from at least 3 mice. n.d., not detected. $P=0.53$, NT versus STT in WT mice. (B) Immunofluorescence staining of ICAM-1 (red) and CD31 (green) in WT and I/ $6^{-/-}$mice implanted with B16 tumors. Numbers denote MFI for CD31+ vessels. Scale bar: $100 \mu \mathrm{m}$. (C) Quantification of endogenous CD8 ${ }^{+}$T cells in B16 tumors. Data are from individual mice and are representative of at least 3 independent experiments. ${ }^{*} P<0.0001$ versus NT. (D) Quantitative image analysis for ICAM-1 and CD31 staining of B16 tumor vessels in bone marrow chimeric mice. Numbers denote MFI for CD31+ vessels.

Results in multiple solid tumor models provide definitive evidence that tumor vessels are sites of low constitutive $\mathrm{CD}^{+}$Teff recruitment despite the presence of functionally active inflammatory cytokines in the microenvironment. Direct imaging in tumor vessels revealed that $\mathrm{CD}^{+}$Teffs engaged in minimal E/P-selectin-mediated rolling interactions under homeostatic conditions and rarely underwent chemokine-dependent transition to ICAM-1-mediated firm arrest. These results are in agreement with previous reports showing limited leukocyte-tumor vessel interactions when whole blood leukocyte populations were labeled with rhodamine-6-G in situ $(19-21,36,37)$. We further determined that the moderate intravascular density of ICAM-1 detected on tumor vessels was not sufficient to support efficient extravasation of CD8 ${ }^{+}$Teffs. These findings provide a functional explanation for the modest steadystate level of infiltration observed for endogenous or adoptively transferred CD8 ${ }^{+} \mathrm{T}$ cells in murine tumors (B16, RIP-Tag5) (27, $28,36,38$ ) or patient tumors (metastatic melanoma, squamous cell skin carcinoma) $(39,40)$ in regions where vessels were weakly immunostained for E-selectin, ICAM-1, or VCAM-1. When the function of tumor-reactive $\mathrm{T}$ cells was monitored after bolus infusion under conditions commonly used in preclinical and clinical protocols to boost circulating Teff populations (3), we found that basal trafficking of $\mathrm{CD}^{+}$Teffs across tumor vessels was insufficient to mediate apoptosis of tumor targets. Collectively, these results indicate that low homeostatic $\mathrm{CD}^{+} \mathrm{T}$ cell trafficking is a rate-limiting step during the effector phase of antitumor immunity.
The current study demonstrated that acute inflammatory cues triggered by STT substantially increase the multistep recruitment of $\mathrm{CD}^{+}$Teffs across tumor vessels. These observations led to the identification of a role for endogenous IL- 6 acting in concert with sIL-6R and the membrane-anchored gp130 signaltransducing receptor in promoting extravasation of CD8 ${ }^{+}$Teffs within the tumor microenvironment. IL- 6 trans-signaling controlled discrete steps in the adhesion cascade, improving both E/P-selectin-mediated rolling interactions and ICAM-1-dependent firm arrest of $\mathrm{CD}^{+}$Teffs at the tumor vascular interface. Our present data further established a direct link between IL-6 induction of $\mathrm{CD}^{+}$Teff trafficking and antigen-specific apoptosis in tumor targets. While increases in vascular endothelial adhesion were obligatory for trafficking of cytotoxic $T$ cells, this does not exclude the possibility that additional changes in vessel function or $\mathrm{T}$ cell fate occur as a consequence of thermal preconditioning of the tumor microenvironment. In this regard, STT reportedly increases tumor vessel permeability and reduces intratumoral interstitial fluid pressure, both of which could facilitate $\mathrm{CD}^{+} \mathrm{T}$ cell extravasation (41-43). Moreover, STT acting via IL-6 could theoretically influence $\mathrm{T}$ cell survival (known to be sensitive to IL-6/STAT3 signaling; ref. 44), interstitial migration by $\mathrm{T}$ cells, and frequency or duration of contacts between $\mathrm{CD} 8^{+}$ Teffs and tumor targets. Multiphoton intravital imaging in subcutaneous EG7-OVA thymomas have documented the importance of reduced $\mathrm{T}$ cell velocity $(\sim 4 \mu \mathrm{m} / \mathrm{min})$ and the formation 

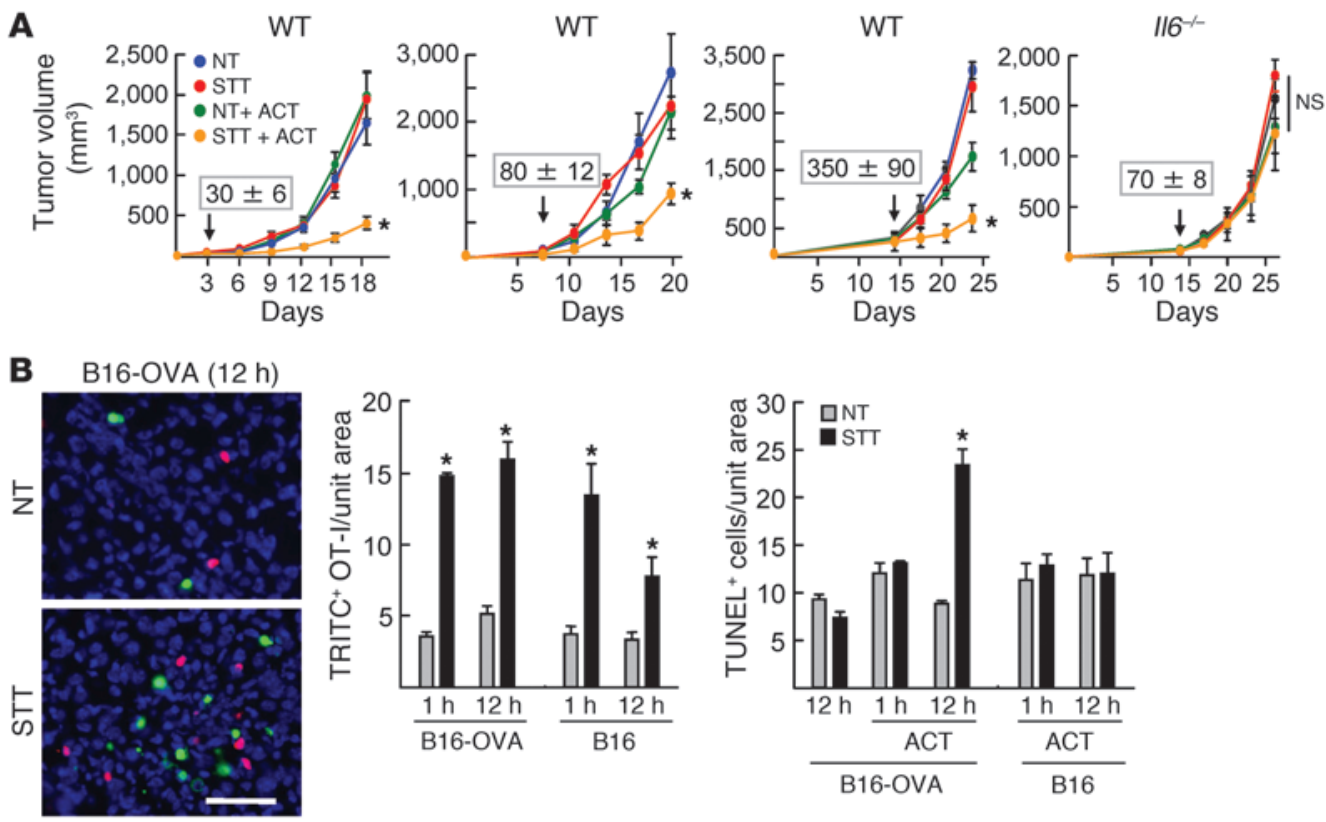

TRITC/TUNEL/DAPI
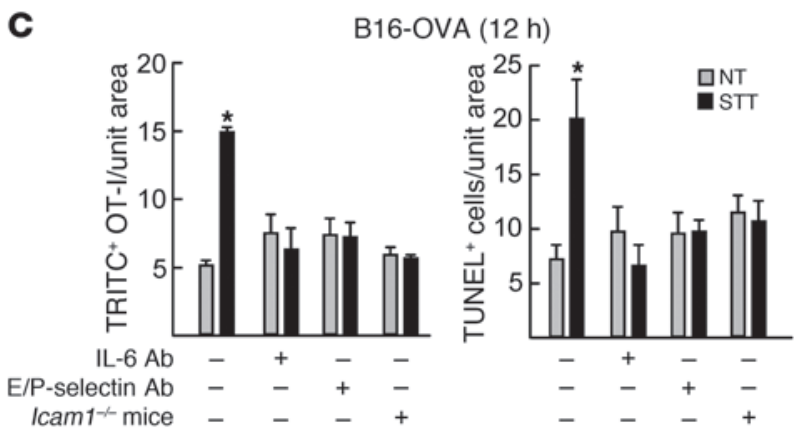

\section{Figure 8}

Antigen-restricted killing of tumor targets depends on CD8+ T cell trafficking across tumor vessels. (A) Growth curves of B16-OVA tumors in mice treated with STT and adoptive cell transfer (ACT) of OT-I effector cells. Treatment times are denoted by arrows; numbers above arrows indicate tumor volume at the time of treatment. $n=5$ mice per condition. ${ }^{*} P<0.04$ versus NT plus ACT. (B) Representative photomicrographs of B16-OVA tumors 12 hours after adoptive transfer of TRITC-labeled OT-I cells (red). Apoptotic cells were detected by TUNEL assay (green), and nucleated cells were stained with DAPI (blue). Scale bar: $100 \mu \mathrm{m}$. Quantification of intratumoral TRITC+ OT-I cells and TUNEL ${ }^{+}$apoptotic cells at 1 or 12 hours after adoptive transfer is also shown. (C) Neutralizing antibody specific for IL-6 or E/P-selectin was administered intravenously 30 minutes before STT treatment in B16-OVA tumor-bearing WT mice. Tumors were also implanted in Icam $1^{-/-}$mice. (B and C) Data are from individual mice and are representative of at least 3 independent experiments. ${ }^{*} P<0.002$ versus NT.

of long-lived contacts ( $\geq 30$ minutes) for tumor cell destruction by adoptively transferred $\mathrm{CD}^{+} \mathrm{T}$ cells $(11,31,45)$.

Increased $\mathrm{CD}^{+}$Teff trafficking during STT was accompanied by a decrease in Treg infiltration, thereby augmenting the endogenous Tem/Treg ratio (from about 5:1 to more than 35:1), which is considered a strong prognostic indicator of overall survival in cancer patients (46). Tregs reportedly diminish $\mathrm{CD}^{+} \mathrm{T}$ cell cytotoxicity by preventing the release of granzyme B effector molecules without affecting stable contacts with tumor targets (47). Thus, a net increase in the proportion of intratumoral Tems relative to Tregs would be predicted to enhance the efficacy of adoptive $T$ cell therapy. An unresolved question is whether the observed decrease in Treg infiltration is caused by reduced Treg trafficking across vascular barriers, egress from tumor lesions, or reprogram- ming in situ. Of note in this respect are studies showing that IL-6 converts immunosuppressive Tregs into IL-17-producing CD4+ $\mathrm{T}$ cell subsets with helper and/or proinflammatory activity and that the IL-6/sIL-6R complex is more effective than IL-6 alone (48-50). Evidence of longitudinal tumor growth despite STT/adoptive transfer therapy could reflect reestablishment of an immunosuppressive environment in situ that subverts the antitumor activity of transferred CD8 ${ }^{+}$Teffs. Thus, further therapeutic benefit might be achieved by repeated STT/adoptive transfer treatment in a setting of micrometastases or minimal residual disease coupled with additional strategies that interfere with immunosuppressive activities of Tregs or MDSCs in the tumor microenvironment.

The stringent requirement for 2 independent soluble components, IL-6 and sIL-6R, during STT likely explains the site-spe- 


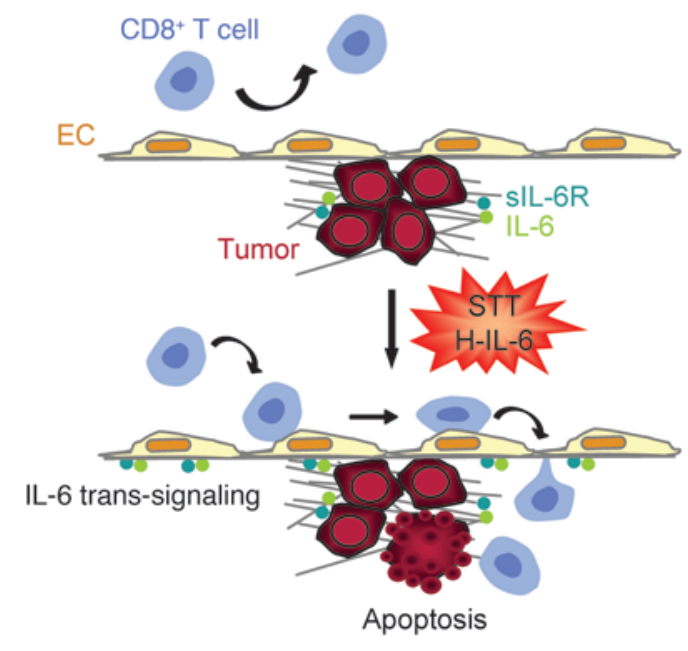

Figure 9

Proposed model for switch from predominantly protumorigenic to antitumorigenic activity of IL-6 trans-signaling via mobilization of CD8+ $\mathrm{T}$ cell trafficking across vascular EC gateways.

cific nature of the vascular response that focuses delivery of $\mathrm{CD}^{+}$ Teffs to tumor sites. Thermal induction of gp130 expression on tumor vessels may be a mechanism to increase sensitivity to stromally derived IL-6. These results are consistent with reports that gp130 synthesis is inducible by inflammatory cytokines and that cells with elevated gp130 have a lower threshold for activation by IL- 6 family cytokines $(51,52)$. The failure of normal vessels of extralymphoid organs as well as HEVs to support efficient CD8 ${ }^{+}$ Teff trafficking in response to STT does not appear to reflect an intrinsic inability to respond to IL- 6 trans-signaling, since ICAM-1 induction has been reported in normal vascular ECs in vivo and in vitro after stimulation by IL- 6 and sIL-6R, but not IL- 6 alone (12, $15,53)$. Indeed, IL-6 trans-signaling is responsible for the increase in naive and central memory $\mathrm{T}$ cell trafficking that occurs in HEVs during STT $(12,15-17)$. These observations imply that coordinate upregulation of trafficking molecules (E/P-selectin, ICAM-1) necessary for $\mathrm{CD}^{+}$Teff recruitment depends on temporal/spatial availability of both IL- 6 and sIL-6R in the local vicinity along with yet to be identified tumor microenvironmental factors.

Demonstration of the promigratory role of IL- 6 in the current study adds to the expanding repertoire of activities attributed to IL-6 in the tumor microenvironment. Studies reported here and by others indicate that IL- 6 functions as a double-edged sword, on the one hand promoting $\mathrm{T}$ cell-mediated antitumor immunity, while on the other contributing to inflammation-associated tumorigenesis $(1,2)$. These latter observations are consistent with the correlation between high circulating levels of IL-6 and poor prognosis in cancer patients $(54,55)$. In murine models and in human colorectal, breast, and hepatocellular carcinoma, STAT3 activation in tumor cells by IL- 6 produced by infiltrating myeloid cells, CD4 ${ }^{+} \mathrm{T}$ cells, or cancer cells leads to induction of target genes that promote oncogenic transformation, proliferation (cyclin D1, c-Myc), and survival (bcl-XL, survivin) (56-62). IL-6 is also implicated in promoting tumor growth by stimulation of VEGF synthesis, attraction of aggressive circulating tumor cells during selfseeding, or immunosuppression caused by arrested maturation of dendritic cells (63-65). Thus, long-term therapy aimed at sus- taining IL- 6 activation would not be indicated in cancer patients. However, the current study suggests that a therapeutic opportunity is afforded by approaches such as STT or recombinant H-IL-6 administration that transiently activate an IL-6 trans-signaling platform, thereby improving adaptive antitumor immunity without stimulating tumor growth.

Findings here and in other studies $(56,59,62,66)$ that IL-6 trans-signaling occurred constitutively in tumor tissues raise the question of why trafficking molecules are not continuously upregulated on murine or human tumor vessels, as would be predicted at chronic inflammatory sites. A likely explanation is that suppressive factors within the tumor microenvironment counteract IL-6 activity. Angiogenic factors (VEGF, bFGF) and regulators of vascular tone (endothelin, NO) are known to repress ICAM-1 or E-selectin induction by inflammatory stimuli (TNF, IL-1 $\beta$, LPS) in ECs in vitro $(7,21,67)$. Moreover, systemic administration of angiogenic inhibitors (anginex, endostatin, angiostatin) or a NO synthase inhibitor (L-NAME) augments TNF or LPS-induced leukocyte interactions in B16 or HT29 tumor vessels. Infiltration of adoptively transferred $\mathrm{CD}^{+} \mathrm{T}$ cells in murine ID8 ovarian tumors and RIP-Tag5 tumors is also improved by targeting of 2 tumor vessel-associated GPCRs that control vascular tone: endothelin B receptor, by BQ-788 antagonist, and RGS5, by genetic deletion $(7,9)$. Cross-talk with local immunosuppressive cytokines such as TGF- $\beta$ could further antagonize IL- 6 trans-signaling (1). TGF- $\beta$ represses IL-6-dependent activation of STAT3 and subsequent ICAM-1 induction in colon cancer cells in vitro (68), which suggests that similar antagonistic mechanisms might operate in tumor microvascular ECs. Of note in this regard are observations that TGF- $\beta$ neutralization enhances leukocyte adhesion in HT29 tumor microvessels (19). Future investigation will be required to determine (a) whether the STT/IL-6 pathway interferes with the expression and/or function of one or more of these antimigratory molecules, and (b) whether IL- 6 contributes to increased expression of trafficking molecules (E-selectin, ICAM-1, VCAM-1) and $\mathrm{CD}^{+} \mathrm{T}$ cell infiltration in the tumor microenvironment during irradiation or CTLA-4 blockade in tumor-bearing mice or local administration of TLR agonists (e.g., imiquimod) in melanoma patients $(28,36,38,40,69)$.

In summary, our results establish that limitations in $\mathrm{CD}^{+}$ Teff trafficking across tumor vessels are a substantial obstacle to $\mathrm{CD}^{+} \mathrm{T}$ cell-mediated tumor immunity. There is growing interest in optimizing the homing potential of Teffs during ex vivo expansion prior to adoptive transfer or by genetically engineering $T$ cells to express homing receptors (e.g., $\alpha v \beta 3$ ligands, CCR2, or CCR4) that favor localization in tumor sites $(3,70-72)$. Our studies argue that it will be equally important to license tumor microvascular checkpoints for $\mathrm{CD}^{+}$Teff trafficking. Thermal therapy has already shown clinical benefit as an adjuvant to radiation or chemotherapy (73-75), which suggests that this modality could be used to co-opt IL-6 in the tumor microenvironment in order to create a therapeutic window to boost $\mathrm{T}$ cell-mediated cancer immunity and immunotherapy in patients.

\section{Methods}

Animals and tumor models. See Supplemental Methods.

Cell culture. Mouse cells were cultured in RPMI 1640 supplemented with $10 \%$ FCS, $2 \mathrm{mM}$ L-glutamine, $100 \mathrm{U} / \mathrm{ml}$ penicillin, $50 \mu \mathrm{g} / \mathrm{ml}$ streptomycin, and $50 \mu \mathrm{M} \beta$-mercaptoethanol (Invitrogen). Primary $\mathrm{CD}^{+} \mathrm{T}$ cells $\left(2 \times 10^{6}\right.$ cells $\left./ \mathrm{ml}\right)$ were activated for 2 days in 24 -well plates (Corning) coated 
with anti-mouse CD3 antibody $(2.5 \mu \mathrm{g} / \mathrm{ml}$; $145-2 \mathrm{C} 11$; BD Biosciences), then diluted to $2 \times 10^{5}$ cells $/ \mathrm{ml}$ and expanded for 3 days with recombinant human IL-2 (12.5 ng/ml; R\&D Systems). All antibodies and cytokines were azide and endotoxin free.

Treatment with STT, LPS, H-IL-6, and cytokine- or adhesion-neutralizing reagents. Mice were treated with STT (core temperature $39.5^{\circ} \mathrm{C} \pm 0.5^{\circ} \mathrm{C}$ for 6 hours) and allowed to return to baseline temperature prior to further experimentation (15-17). LPS ( $1 \mathrm{mg} / \mathrm{kg}$; Sigma-Aldrich) was injected intraperitoneally. Neutralizing polyclonal antibodies specific for IL-6, TNF, IL-1 $\beta$, or IFN- $\gamma(100 \mu \mathrm{g} /$ mouse; R\&D Systems); recombinant sgp130 (2.5 $\mu \mathrm{g} / \mathrm{mouse}$; ref. 32); or recombinant H-IL-6 (50 $\mu \mathrm{g} / \mathrm{kg}$; ref. 33) were administered intravenously. Tumor explants from stage IV colorectal cancer patients $\left(-0.25-1 \mathrm{~cm}^{3}\right)$ were cultured in RPMI 1640 supplemented by $10 \%$ FCS with H-IL-6 $(1 \mu \mathrm{g} / \mathrm{ml})$ for 6 hours at $37^{\circ} \mathrm{C}$. Mice were treated intravenously with function-blocking antibodies (BD Biosciences) specific for E- and P-selectin (10E9.6 and RB40.3; 60 and $40 \mu \mathrm{g} /$ mouse, respectively), ICAM-1 (3E2; $50 \mu \mathrm{g} /$ mouse), or isotype controls. $\mathrm{CD}^{+} \mathrm{T}$ cells were treated with $\alpha 4 \beta 7$ integrin-specific antibody (DAKT32; $10 \mu \mathrm{g} / \mathrm{ml}, 30$ minutes; BD Biosciences) or PTX $(100 \mathrm{ng} / \mathrm{ml}$, 2 hours; CalBiochem) before transfer. All cytokines and neutralizing agents were azide and endotoxin free.

Cytokine assays. Cytokines were measured by ELISA or Luminex kits (R\&D Systems), and results were normalized to total protein from tissue extracts.

Short-term in vivo homing assay. $\mathrm{CD}^{+} \mathrm{T}$ cells labeled with $4 \mu \mathrm{M}$ TRITC (Invitrogen) were adoptively transferred intravenously, and organs were collected 1 hour later $(15-17)$. Tissue cryosections $(9 \mu \mathrm{m})$ were counterstained with anti-CD31 antibody (MEC 13.3; BD Biosciences). For consistency, fields containing a minimum of 1 TRITC-labeled cell were imaged by observers blinded to sample identity using a BH2/RFL fluorescence microscope (Olympus Optical) and SPOT RT camera (Diagnostic Instruments). TRITC-labeled cells were quantified in at least 10 fields (unit area per field, $0.34 \mathrm{~mm}^{2}$ ). Alternatively, organs were disaggregated (Medimachine; BD Biosciences), and total cell numbers were determined by flow cytometry using Stem-Count beads (Beckman Coulter) (15). T cell distribution within tumors was examined using a procedure modified from that of Boissonnas et al. (11). OCT-embedded tumors were transversally and sagitally divided through the middle; the center and periphery (in $9-\mu \mathrm{m}$ sections) were defined as regions within $600 \mu \mathrm{m}$ of the core or the tumor boundary, respectively.

Flow cytometry. See Supplemental Methods.

Intravital microscopy. See Supplemental Methods for additional details. Briefly, $10^{5}$ tumor cells were injected into surgically implanted dorsal skin flap single-sided window chambers (Research Instruments Inc.) $(20,37)$. 14-21 days later, calcein-labeled T cells $\left(2-10 \times 10^{7}\right.$ cells/mouse $)$ were gradually injected via the tail vein of anesthetized mice $(1 \mathrm{mg} / \mathrm{ml}$ xylazine and $10 \mathrm{mg} / \mathrm{ml}$ ketamine; $10 \mathrm{ml} / \mathrm{kg}$, i.p.) over the 30 -minute observation period. $\mathrm{T}$ cell interactions in unbranched vascular segments $100 \mu \mathrm{m}$ in length with 5-40 $\mu \mathrm{m}$ diameter were visualized using a customized Olympus BX51WI epi-illumination intravital microscopy system (Spectra Services). Vessels greater than $40 \mu \mathrm{m}$ in diameter ( $<4 \%$ of observable vasculature) were excluded because of difficulties for imaging intravascular $T$ cells. The percentage of total cells that interacted per microvessel was considered the rolling fraction; the percentage of rolling cells that subsequently adhered for at least 30 seconds was considered the sticking fraction (15).
Immunohistochemistry and immunofluorescence histology. See Supplemental Methods for details on immunostaining of tissue sections and tissue whole mounts. Images of at least 10 randomly selected fields (unit area of each field, $0.34 \mathrm{~mm}^{2}$ ) in $9-\mu \mathrm{m}$-thick cryosections were captured by observers blinded to sample identity. Identical exposure times and image settings were used within each experiment. Images were analyzed with ImageJ software (http://rsb.info.nih.gov/ij) $(15,76)$ for determination of the relative fluorescence staining intensity; regions of interest were defined based on CD31 fluorescence, and each pixel in identified regions was assigned a fluorescence intensity value (based on a scale from 0 to 255).

Growth delay studies and TUNEL assay. A subcurative dose of OT-I or Clone 4 Teffs (ranging 2-10 $\times 10^{6}$ cells/mouse) was determined for each adoptive transfer experiment. Experimental end points were reached when tumors in any group exceeded $20 \mathrm{~mm}$ in diameter or when mice became moribund. The length of short $(l)$ and long $(L)$ diameters was determined, and tumor volume was calculated as $l^{2} \times L / 2$. For apoptosis studies, $2 \times 10^{7}$ OT-I Teffs were adoptively transferred, and $\mathrm{TUNEL}^{+}$cells (Apoptag Kit; Millipore) were quantified in at least 10 fields (unit area of each field, $0.34 \mathrm{~mm}^{2}$ ) of nonsequential 9- $\mu \mathrm{m}$-thick cryosections.

Statistics. Unless otherwise indicated, data are mean \pm SEM. Statistical significance of tumor growth was determined by 2 -way ANOVA for repeated measures. All other group differences were evaluated by 2 -tailed unpaired Student's $t$ test. Survival data were analyzed using Kaplan-Meier log rank tests. A $P$ value less than 0.05 was considered significant.

Study approval. Animal protocols were approved by the IACUC of Roswell Park Cancer Institute. Patient tumors were obtained following written informed consent in accordance with tissue procurement protocols approved by the IRB of Roswell Park Cancer Institute.

\section{Acknowledgments}

We thank P.K. Wallace, E.A. Timm, and R. Dolnick for assistance with flow cytometry and confocal microscopy; M. Mikucki for critical reading of the manuscript; K.A. Clancy for immunofluorescence histology; S. Abrams and J. Waight for guidance on the analysis of MDSCs; X. Cao for advice on Treg and granzyme B immunostaining; and D. Hanahan (UCSF) for helpful discussions on the manuscript. This work was supported by the NIH (CA79765, CA094045, and AI082039 to S.S. Evans; CA098156 to S.O. Gollnick; CA42745 to M.W. Dewhirst; CA094045 and CA071599 to E.A. Repasky; DK33886 and CA85580 to H. Baumann), the Department of Defense (W81XWH-04-1-0354 to Q. Chen), the Roswell Park Alliance Foundation (to S.S. Evans), the Jennifer Linscott Tietgen Family Foundation (to S.S. Evans and J.J. Skitzki), the Deutsche Forschungsgemeinschaft (SFB414, TP B5), and the Cluster of Excellence "Inflammation at Interfaces" (to S. Rose-John).

Received for publication August 30, 2010, and accepted in revised form August 3, 2011.

Address correspondence to: Sharon S. Evans, Department of Immunology, Roswell Park Cancer Institute, Buffalo, New York 14263, USA. Phone: 716.845.3421; Fax: 716.845.1322; E-mail: sharon.evans@roswellpark.org.
1. Grivennikov SI, Greten FR, Karin M. Immunity, inflammation, and cancer. Cell. 2010;140(6):883-899.

2. Silver JS, Hunter CA. gp130 at the nexus of inflammation, autoimmunity, and cancer. J Leukoc Biol. 2010;88(6):1145-1156.

3. Rosenberg SA, Restifo NP, Yang JC, Morgan RA,
Dudley ME. Adoptive cell transfer: a clinical path to effective cancer immunotherapy. Nat Rev Cancer. 2008;8(4):299-308.

4. Boon T, Coulie PG, Eynde BJ, Bruggen PV. Human $\mathrm{T}$ cell responses against melanoma. Annu Rev Immunol. 2006;24:175-208.
5. Galon J, et al. Type, density, and location of immune cells within human colorectal tumors predict clinical outcome. Science. 2006;313(5795):1960-1964.

6. Piras F, et al. The predictive value of CD8, CD4, CD68, and human leukocyte antigen-D-related cells in the prognosis of cutaneous malignant mel- 
anoma with vertical growth phase. Cancer. 2005; 104(6):1246-1254

7. Buckanovich RJ, et al. Endothelin B receptor mediates the endothelial barrier to $\mathrm{T}$ cell homing to tumors and disables immune therapy. Nat Med.2008; 14(1):28-36.

8. Morgan RA, et al. Cancer regression in patients after transfer of genetically engineered lymphocytes. Science. 2006;314(5796):126-129.

9. Hamzah J, et al. Vascular normalization in Rgs5deficient tumours promotes immune destruction. Nature. 2008;453(7193):410-414.

10. Mlecnik B, et al. Biomolecular network reconstruction identifies T-cell homing factors associated with survival in colorectal cancer. Gastroenterology. 2010; 138(4):1429-1440

11. Boissonnas A, Fetler L, Zeelenberg IS, Hugues S, Amigorena S. In vivo imaging of cytotoxic T cell infiltration and elimination of a solid tumor. J Exp Med. 2007;204(2):345-356.

12. Vardam TD, et al. Regulation of a lymphocyteendothelial-IL- 6 trans-signaling axis by fever-range thermal stress: hot spot of immune surveillance. Cytokine. 2007;39(1):84-96.

13. von Andrian UH, Mempel TR. Homing and cellular traffic in lymph nodes. Nat Rev Immunol. 2003; 3(11):867-878.

14. Kupper TS, Fuhlbrigge RC. Immune surveillance in the skin: mechanisms and clinical consequences. Nat Rev Immunol. 2004;4(3):211-222.

15. Chen Q, et al. Fever-range thermal stress promotes lymphocyte trafficking across high endothelial venules via an interleukin 6 trans-signaling mechanism. Nat Immunol. 2006;7(12):1299-1308.

16. Evans SS, Wang WC, Bain MD, Burd R, Ostberg JR, Repasky EA. Fever-range hyperthermia dynamically regulates lymphocyte delivery to high endothelial venules. Blood. 2001;97(9):2727-2733

17. Chen Q, et al. Thermal facilitation of lymphocyte trafficking involves temporal induction of intravascular ICAM-1. Microcirculation. 2009;16(2):143-158.

18. Davenpeck KL, Zagorski J, Schleimer RP, Bochner BS. Lipopolysaccharide-induced leukocyte rolling and adhesion in the rat mesenteric microcirculation: regulation by glucocorticoids and role of cytokines. J Immunol. 1998;161(12):6861-6870.

19. Bessa X, et al. Leukocyte recruitment in colon cancer: role of cell adhesion molecules, nitric oxide, and transforming growth factor beta1. Gastroenter ology. 2002;122(4):1122-1132.

20. Wu NZ, Klitzman B, Dodge R, Dewhirst MW. Diminished leukocyte-endothelium interaction in tumor microvessels. Cancer Res. 1992;52(15):4265-4268

21. Dirkx AE, et al. Anti-angiogenesis therapy can overcome endothelial cell anergy and promote leukocyte-endothelium interactions and infiltration in tumors. FASEB J. 2006;20(6):621-630.

22. Kraybill WG, et al. A phase I study of fever-range whole body hyperthermia (FR-WBH) in patients with advanced solid tumours: correlation with mouse models. Int J Hyperthermia. 2002;18(3):253-266.

23. Burd R, Dziedzic TS, Xu Y, Caligiuri MA, Subjeck JR, Repasky EA. Tumor cell apoptosis, lymphocyte recruitment and tumor vascular changes are induced by low temperature, long duration (feverlike) whole body hyperthermia. J Cell Pbysiol. 1998; 177(1):137-147.

24. Ostberg JR, Ertel BR, Lanphere JA. An important role for granulocytes in the thermal regulation of colon tumor growth. Immunol Invest. 2005;34(3):259-272.

25. Hanahan D. Heritable formation of pancreatic $\beta$-cell tumours in transgenic mice expressing recombinant insulin/simian virus 40 oncogenes. Nature. 1985;315(6015):115-122.

26. Spring H, Schuler T, Arnold B, Hammerling GJ, Ganss R. Chemokines direct endothelial progenitors into tumor neovessels. Proc Natl Acad Sci US A. 2005;102(50):18111-18116
27. Onrust SV, Hartl PM, Rosen SD, Hanahan D. Modulation of L-selectin ligand expression during an immune response accompanying tumorigenesis in transgenic mice. J Clin Invest. 1996;97(1):54-64.

28. Quezada SA, Peggs KS, Simpson TR, Shen Y, Littman DR, Allison JP. Limited tumor infiltration by activated Teffs restricts the therapeutic activity of regulatory $\mathrm{T}$ cell depletion against established melanoma. J Exp Med. 2008;205(9):2125-2138.

29. Vicari AP, Ait-Yahia S, Chemin K, Mueller A, Zlotnik A, Caux C. Antitumor effects of the mouse chemokine 6Ckine/SLC through angiostatic and immunological mechanisms. J Immunol. 2000; 165(4):1992-2000.

30. Andrew DP, et al. Distinct but overlapping epitopes are involved in $\alpha 4 \beta 7$-mediated adhesion to vascular cell adhesion molecule-1, mucosal addressin-1, fibronectin, and lymphocyte aggregation. J Immunol. 1994;153(9):3847-3861.

31. Breart B, Lemaitre F, Celli S, Bousso P. Two-photon imaging of intratumoral $\mathrm{CD}^{+} \mathrm{T}$ cell cytotoxic activity during adoptive $\mathrm{T}$ cell therapy in mice. J Clin Invest. 2008;118(4):1390-1397.

32. Jostock T, et al. Soluble gp130 is the natural inhibitor of soluble interleukin- 6 receptor transsignaling responses. Eur J Biochem. 2001;268(1):160-167.

33. Fischer $M$, et al. I. A bioactive designer cytokine for human hematopoietic progenitor cell expansion. Nat Biotechnol. 1997;15(2):142-145.

34. Ozbek S, et al. The designer cytokine hyper-IL-6 mediates growth inhibition and GM-CSF-dependent rejection of B16 melanoma cells. Oncogene. 2001; 20(8):972-979.

35. Rabinovich GA, Gabrilovich D, Sotomayor EM. Immunosuppressive strategies that are mediated by tumor cells. Annu Rev Immunol. 2007;25:267-296.

36. Ganss R, Ryschich E, Klar E, Arnold B, Hammerling GJ. Combination of T-cell therapy and trigger of inflammation induces remodeling of the vasculature and tumor eradication. Cancer Res. 2002; 62(5):1462-1470

37. Fisher DT, et al. Hurdles to lymphocyte trafficking in the tumor microenvironment: implications for effective immunotherapy. Immunol Invest. 2006; 35(3-4):251-277.

38. Lugade AA, Sorensen EW, Gerber SA, Moran JP, Frelinger JG, Lord EM. Radiation-induced IFN- $\gamma$ production within the tumor microenvironment influences antitumor immunity. J Immunol. 2008 180(5):3132-3139.

39. Weishaupt C, Munoz KN, Buzney E, Kupper TS, Fuhlbrigge RC. T-cell distribution and adhesion receptor expression in metastatic melanoma. Clin Cancer Res. 2007;13(9):2549-2556

40. Clark RA, et al. Human squamous cell carcinomas evade the immune response by down-regulation of vascular E-selectin and recruitment of regulatory T cells. J Exp Med. 2008;205(10):2221-2234

41. Kong G, Braun RD, Dewhirst MW. Characterization of the effect of hyperthermia on nanoparticle extravasation from tumor vasculature. Cancer Res. 2001; 61(7):3027-3032

42. Xu Y, et al. Fever-range whole body hyperthermia increases the number of perfused tumor blood vessels and therapeutic efficacy of liposomally encapsulated doxorubicin. Int J Hyperthermia. 2007; 23(6):513-527.

43. Sen A, et al. Mild elevation of body temperature reduces tumor interstitial fluid pressure and hypoxia and enhances efficacy of radiotherapy in murine tumor models. Cancer Res. 2011;71(11):3872-3880.

44. Atreya R, et al. Blockade of interleukin 6 trans signaling suppresses $\mathrm{T}$-cell resistance against apoptosis in chronic intestinal inflammation: evidence in crohn disease and experimental colitis in vivo. Nat Med. 2000;6(5):583-588.

45. Mrass $\mathrm{P}$, et al. Random migration precedes stable target cell interactions of tumor-infiltrating $\mathrm{T}$ cells.
J Exp Med. 2006;203(12):2749-2761.

46. Sato E, et al. Intraepithelial CD8+ tumor-infiltrating lymphocytes and a high CD8+/regulatory $\mathrm{T}$ cell ratio are associated with favorable prognosis in ovarian cancer. Proc Natl Acad Sci U S A. 2005; 102(51):18538-18543.

47. Mempel TR, et al. Regulatory $\mathrm{T}$ cells reversibly suppress cytotoxic $T$ cell function independent of effector differentiation. Immunity. 2006;25(1):129-141.

48. Sharma MD, et al. Reprogrammed foxp3(+) regulatory $\mathrm{T}$ cells provide essential help to support crosspresentation and CD8 $(+) \mathrm{T}$ cell priming in naive mice. Immunity. 2010;33(6):942-954.

49. Yang XO, et al. Molecular antagonism and plasticity of regulatory and inflammatory $\mathrm{T}$ cell programs. Immunity. 2008;29(1):44-56.

50. Dominitzki S, et al. Cutting edge: trans-signaling via the soluble IL-6R abrogates the induction of FoxP3 in naive CD4+CD25 T cells. J Immunol. 2007; 179(4):2041-2045.

51. Klouche M, Bhakdi S, Hemmes M, Rose-John S. Novel path to activation of vascular smooth muscle cells: up-regulation of gp130 creates an autocrine activation loop by IL- 6 and its soluble receptor. J Immunol. 1999;163(8):4583-4589.

52. Schooltink H, Schmitz-Van de Leur H, Heinrich PC, Rose-John S. Up-regulation of the interleukin-6-signal transducing protein (gp130) by interleukin-6 and dexamethasone in HepG2 cells. FEBS Lett. 1992;297(3):263-265

53. Romano M, et al. Role of IL- 6 and its soluble receptor in induction of chemokines and leukocyte recruitment. Immunity. 1997;6(3):315-325.

54. Esfandi F, Mohammadzadeh Ghobadloo S, Basati G. Interleukin-6 level in patients with colorectal cancer. Cancer Lett. 2006;244(1):76-78.

55. Knupfer H, Preiss R. Significance of interleukin-6 (IL-6) in breast cancer (review). Breast Cancer Res Treat. 2007;102(2):129-135.

56 . Becker C, et al. TGF- $\beta$ suppresses tumor progression in colon cancer by inhibition of IL- 6 trans-signaling. Immunity. 2004;21(4):491-501.

57. Iliopoulos D, Hirsch HA, Struhl K. An epigenetic switch involving NF-KB, Lin28, Let-7 MicroRNA, and IL6 links inflammation to cell transformation. Cell. 2009;139(4):693-706

58. Park EJ, et al. Dietary and genetic obesity promote liver inflammation and tumorigenesis by enhancing IL-6 and TNF expression. Cell. 2010;140(2):197-208.

59. Grivennikov S, et al. IL- 6 and Stat 3 are required for survival of intestinal epithelial cells and development of colitis-associated cancer. Cancer Cell. 2009; 15(2):103-113.

60. Maeda S, Kamata H, Luo JL, Leffert H, Karin M. IKK couples hepatocyte death to cytokine-driven compensatory proliferation that promotes chemical hepatocarcinogenesis. Cell. 2005;121(7):977-990.

61. Bollrath J, et al. gp130-mediated Stat3 activation in enterocytes regulates cell survival and cell-cycle progression during colitis-associated tumorigenesis. Cancer Cell. 2009;15(2):91-102.

62. Lesina M, et al. Stat3/Socs3 activation by IL-6 transsignaling promotes progression of pancreatic intraepithelial neoplasia and development of pancreatic cancer. Cancer Cell. 2011;19(4):456-469.

63. Yeh HH, Lai WW, Chen HH, Liu HS, Su WC. Autocrine IL-6-induced Stat 3 activation contributes to the pathogenesis of lung adenocarcinoma and malignant pleural effusion. Oncogene. 2006; 25(31):4300-4309.

64. Kim MY, et al. Tumor self-seeding by circulating cancer cells. Cell. 2009;139(7):1315-1326

65. Chomarat P, Banchereau J, Davoust J, Palucka AK. IL- 6 switches the differentiation of monocytes from dendritic cells to macrophages. Nat Immunol. 2000; 1(6):510-514

66. Matsumoto S, et al. Essential roles of IL-6 transsignaling in colonic epithelial cells, induced by the 
IL-6/soluble-IL-6 receptor derived from lamina propria macrophages, on the development of colitis-associated premalignant cancer in a murine model. J Immunol. 2010;184(3):1543-1551.

67. Melder RJ, Koenig GC, Witwer BP, Safabakhsh N, Munn LL, Jain RK. During angiogenesis, vascular endothelial growth factor and basic fibroblast growth factor regulate natural killer cell adhesion to tumor endothelium. Nat Med. 1996;2(9):992-997.

68. Walia B, Wang L, Merlin D, Sitaraman SV. TGF- $\beta$ down-regulates IL- 6 signaling in intestinal epithelial cells: critical role of SMAD-2. FASEB J. 2003; 17(14):2130-2132.

69. Cao ZA, Daniel D, Hanahan D. Sub-lethal radia- tion enhances anti-tumor immunotherapy in a transgenic mouse model of pancreatic cancer. $B M C$ Cancer. 2002;2:11.

70. Legler DF, Johnson-Leger C, Wiedle G, Bron C, Imhof BA. The $\alpha v \beta 3$ integrin as a tumor homing ligand for lymphocytes. Eur J Immunol. 2004; 34(6):1608-1616

71. Craddock JA, et al. Enhanced tumor trafficking of GD2 chimeric antigen receptor T cells by expression of the chemokine receptor CCR2b. J Immunother. 2010;33(8):780-788.

72. Di Stasi A, et al. T lymphocytes coexpressing CCR4 and a chimeric antigen receptor targeting CD30 have improved homing and antitumor activity in a Hodg- kin tumor model. Blood. 2009;113(25):6392-6402.

73. Issels $\mathrm{RD}$, et al. Neo-adjuvant chemotherapy alone or with regional hyperthermia for localised highrisk soft-tissue sarcoma: a randomised phase 3 multicentre study. Lancet Oncol. 2010;11(6):561-570.

74. Jones EL, et al. Randomized trial of hyperthermia and radiation for superficial tumors. J Clin Oncol. 2005;23(13):3079-3085.

75. Peer AJ, Grimm MJ, Zynda ER, Repasky EA. Diverse immune mechanisms may contribute to the survival benefit seen in cancer patients receiving hyperthermia. Immunol Res. 2010;46(1-3):137-154.

76. Abramoff MD, Magelhaes PJ, Ram SJ. Image Processing with ImageJ. Biophotonics Int. 2004;11(7):36-42. 